IZA DP No. 9616

Religion, Discrimination and Trust

Swee Hoon Chuah

Simon Gächter

Robert Hoffmann

Jonathan H. W. Tan

December 2015 


\title{
Religion, Discrimination and Trust
}

\author{
Swee Hoon Chuah \\ RMIT University
}

Simon Gächter

University of Nottingham, IZA and CESifo

Robert Hoffmann

RMIT University

Jonathan H. W. Tan

University of Nottingham

\section{Discussion Paper No. 9616 December 2015}

\author{
IZA \\ P.O. Box 7240 \\ 53072 Bonn \\ Germany \\ Phone: +49-228-3894-0 \\ Fax: +49-228-3894-180 \\ E-mail: iza@iza.org
}

Any opinions expressed here are those of the author(s) and not those of IZA. Research published in this series may include views on policy, but the institute itself takes no institutional policy positions. The IZA research network is committed to the IZA Guiding Principles of Research Integrity.

The Institute for the Study of Labor (IZA) in Bonn is a local and virtual international research center and a place of communication between science, politics and business. IZA is an independent nonprofit organization supported by Deutsche Post Foundation. The center is associated with the University of Bonn and offers a stimulating research environment through its international network, workshops and conferences, data service, project support, research visits and doctoral program. IZA engages in (i) original and internationally competitive research in all fields of labor economics, (ii) development of policy concepts, and (iii) dissemination of research results and concepts to the interested public.

IZA Discussion Papers often represent preliminary work and are circulated to encourage discussion. Citation of such a paper should account for its provisional character. A revised version may be available directly from the author. 
IZA Discussion Paper No. 9616

December 2015

\section{ABSTRACT}

\section{Religion, Discrimination and Trust}

We propose that religion impacts trust and trustworthiness in ways that depend on how individuals are socially identified and connected. Religiosity and religious affiliation may serve as markers for statistical discrimination. Further, affiliation to the same religion may enhance group identity, or affiliation irrespective of creed may lend social identity, and in turn induce taste-based discrimination. Religiosity may also relate to general prejudice. We test these hypotheses across three culturally diverse countries. Participants' willingness to discriminate, beliefs of how trustworthy or trusting others are, as well as actual trust and trustworthiness are measured incentive compatibly. We find that interpersonal similarity in religiosity and affiliation promote trust through beliefs of reciprocity. Religious participants also believe that those belonging to some faith are trustworthier, but invest more trust only in those of the same religion - religiosity amplifies this effect. Across non-religious categories, whereas more religious participants are more willing to discriminate, less religious participants are as likely to display group biases.

JEL Classification: $\quad$ C72, C91, J16, Z12

Keywords: religiosity, connectedness, discrimination, trust, experiment

Corresponding author:

Jonathan $\mathrm{H}$. W. Tan

Centre for Research in the Behavioural Sciences

Nottingham University Business School

Jubilee Campus, Wollaton Road

Nottingham NG8 1BB

United Kingdom

E-mail: Jonathan.Tan@nottingham.ac.uk 


\section{Introduction}

In this paper, we investigate the role of religion-based discrimination in trusting and in trustworthy behaviour when interacting with people from various social groups or cultures. Understanding the role of religion is important, because conflict between and within different religions is rising globally (The Institute for Economics and Peace, 2014; Grim, 2014) and fast becoming a defining feature of the post-cold war world order (Huntington, 1996). A standard manifestation of this religious conflict is inter-religious strife. Another, newer dimension involves religious radicalisation and extremism which can turn individuals against their compatriots and moderate fellow adherents. However, despite its ubiquity, importance and controversy, economists have only recently developed an interest in the effects religion has on economic outcomes (Iannaccone, 1998; Guiso et al., 2006; Tan, 2006). Religion can influence economic behaviour in at least two ways, by creating differential social group identities (Jackson and Hunsberger, 1999) and through individual differences in religiosity, i.e. the strength of an individual's religious attachment or commitment to a particular faith commonly measured as religious belief, ritual and experience (Tan, 2006). Identity (e.g. Akerlof and Kranton, 2000; Chen and Xin, 2009; Currarini and Mengel, 2013) and acculturation (Guiso et al., 2003) generally affect economic outcomes and might act as conduits for the economic influences of religion.

One economic approach to examining these effects is the experimental economics of religion, as critically discussed by Hoffmann (2013) and Tan (2014), where the influences of religious variables on various kinds of individual economic decision are studied systematically in controlled settings. Previous studies demonstrated the first effect, that individuals treat others differently in economic contexts based on same or different religious affiliation even when other social identifiers such as nationality and ethnicity are shared. For example, we conducted a laboratory experiment with student participants from different cross-cutting ethnic and religious groups in Malaysia (Chuah et al., 2014). While participants cooperated relatively more within their own ethnic groups irrespective of religious affiliation, having the same religion as well enhanced their cooperation further. Conversely, participants divided by different ethnic identity cooperated more when they shared religious affiliation. A field experiment where both Indian Hindus and Muslims in Mumbai trusted members of their own religious groups relatively more (Chuah et al., 2013) lends further support.

However, our work as well as that of other researchers failed to demonstrate the second effect, of religiosity, directly. In two experiments participants of higher religiosity were equally cooperative (Chuah et al., 2014) or trusting (Tan and Vogel, 
2008) than others. These results suggest that religiosity, in reflecting an individual's socialisation into and internalisation of particular religious precepts (e.g. Ryan et al., 1993) does not independently affect consequent behaviour. However, both studies provided hints of a second avenue by which religiosity might influence decision making as a vehicle for taste-based or statistical discrimination. One such hint is that among the entirely Christian participant pool of Tan and Vogel (2008), those of known higher religiosity receive greater trust from others, and especially (but not exclusively) from those who share this trait. The second hint is that high religiosity amplified the higher cooperation which Chuah et al.'s (2014) multi-cultural participants paid their religious fellows.

In this paper, we propose that religious identities serve as cues on the nature and degree of connectedness between interacting individuals, and thus religion influences strategic behaviour, in particular trust and trustworthiness on which we focus here. In trust games (Berg et al., 1995; Johnson and Mislin, 2011), a sender decides how much to trust a receiver by sending an amount of money. The receiver receives thrice the amount sent and decides how trustworthy to be in returning a proportion of it. In equilibrium, by backward induction, assuming that receivers are rational and money-maximizing, senders anticipate nothing in return, and so send nothing. Social connectedness is a psychological concept describing the closeness of people e.g. family or acquaintance, friend or foe (Aron et al., 1991). We call closeness in religion-based relationships religious connectedness. Consistent with research on social connectedness in general (Laurenceau et al., 1998), we argue that individual religiosity operates through religious connectedness to affect trust. Religious connectedness increases with the duration and frequency of interactions, knowledge of others, the extent of (mutual) self-disclosure, and the number of people in the other's network one is also connected to. Religious beliefs, rituals, experiences and activities that unite or divide people facilitates this. We consider four forms of religious identity: 1) a connection at the fundamental level of individual religiosity; 2) group membership based on religious affiliation to the same creed; 3) religious affinity arising from the mere affiliation to some religion, regardless of creed; and 4) religious anonymity, where religiosity effects operate on the wider societal level of prejudice across social identities including non-religious ones.

In turn, we examine four corresponding religious discrimination effects on trust and trustworthiness. The first is statistical discrimination (e.g. Mueser, 1999; Anderson et al., 2006), where more religious people are generally believed to be trustworthier and treated accordingly. The second is that religiosity amplifies intergroup bias on the basis of religious affiliation. Intergroup processes including taste-based outgroup discrimination or ingroup favouritism are strengthened by an individual's identification with the group (Farnham et al., 1999; Smurda et al., 2006). 
The third is that religiosity is used as a social identifier of affinity which unites religious people regardless of creed. The fourth is that religiosity is a correlate of greater general prejudice, i.e. discrimination based on social identity differences even in non-religion categories (e.g. Hunsberger and Jackson, 2005).

For this purpose, we conduct a trust game experiment where participants can incur a financial cost in order to discriminate between co-participants of different religions and other social identities. We extend the trust game by allowing participants to make decisions conditional on the social identities of co-participants they might face. We then measure participants' religiosity and consider their religious affiliations, their responses to co-participants of diverse religious affiliations, and corresponding beliefs regarding co-participants' actions. In particular, we study how trustworthy senders think receivers are or how trusting receivers think senders are. We also test how much senders invest trust or receivers reciprocate trust. Further, we analyse whether these beliefs and actions relate to the religiosity and religious affiliation of sender and receiver. This informs us on the relevance of statistical and taste-based motives of discrimination, and whether religiosity per se is related to general prejudice, i.e. on the basis of even non-religious categorisation.

Our design has a number of novel features. In many previous experiments, discrimination was observed in a particular context such as gender or ethnicity. In contrast, we are able to measure discrimination based on different social identifiers which vary within a multi-national participant pool. This allows us to measure discrimination tendencies in a more general way, and to compare these across different social identifiers. Further, we measure discrimination in participants' intention or willingness to discriminate as the resources they are willing to use in order to be able to make decisions contingent on the characteristics of their co-participants. This provides a graduated measure of discrimination intentions, elicited in an incentive compatible way in line with the costliness of discrimination in many real world settings and economic models (see Mueser, 1999). We discuss the literature and motivation in greater detail in section 2. We outline our experiment and hypotheses in section 3 . Results are reported in section 4, before concluding in section 5 .

\section{Religiosity and trust}

Apart from its role in inter-religious conflicts across the world, high religiosity within all creeds plays an important part in a number of pressing contemporary social debates surrounding home-grown terrorism, abortion, contraception and gay rights. These have clear economic consequences. For example, Indiana's Religious 
Freedom Restoration Act allows trade to be refused on religious grounds, while provisions for religious exemptions from public immunisation programmes (in force in 48 U.S. states) can generate negative externalities on an epidemic scale. This provides economists with a clear motivation to examine the effects of religiosity in economic settings using economic methods.

A few experimental economics studies have examined the effects of religiosity (a.k.a. religiousness, which measures an individual's attachment or commitment to a particular faith) on economic behaviour. Most use religious service attendance measures as a proxy and relate this to prosocial behaviour in experimental games. ${ }^{1}$ Generally, previous research has found little evidence for the relationship between religiosity variables and behaviour in the trust game. Fehr et al. (2002) found no effect of the church attendance of German household survey respondents on their decisions in a trust game. Karlan (2005) measured religiosity in terms of months since last religious service attendance and related this variable to public good contributions and trust game decisions in a field experiment in rural Peru. It was inversely related to public good contribution but only at the $10 \%$ level of significance. Attendance also did not explain trust game decisions in this study directly. However, participants with less frequent attendance were sent greater amounts for unexplained reasons. Anderson and Mellor (2009) measured the frequency of religious service attendance to serve as a proxy for religiosity. This variable was not significantly related to public good game contributions of older adult U.S. participants. (Anderson et al., 2010) subsequently found a positive effect with college student participants, but only when comparing the corner cases of high and low attendance. Trust game behaviour here was unrelated to the attendance measure.

Tan (2014) argued that one reason for the mixed results in terms of effect significance and direction could lie in the multi-dimensional nature of religiosity that is not completely captured by simpler measures, e.g. based on attendance alone. Unidimensional religiosity measures like these are unsatisfactory as they fail to tap into the different motivations behind and expressions of religious attachment (Spilka et al. 2003, p. 28; Hill and Hood 1999, p. 5), which can manifest behaviourally in opposite directions (e.g. Tan, 2006). For example, intrinsic spiritual or quest motives for religious attachment are sharply differentiated from extrinsic ones such as seeking social group identification. In response psychologists of religion have developed a now widely-accepted approach (DeJong et al., 1976) which measures individual religiosity in terms of five dimensions, religious knowledge, practice of

\footnotetext{
${ }^{1}$ See the survey by Hoffmann (2013) for more detail on the different behaviour and religious measures used in these studies.
} 
religious activities, belief in religious precepts, personal mystical experience and consequences of religion on behaviour (Glock and Stark, 1965).

We used such multi-dimensional religiosity measures in a number of previous experimental economics studies with promising but still inconclusive results. Tan (2006) found the different components of a multi-dimensional measure to significantly affect dictator game offers or ultimatum game responses but in opposite directions. Chuah et al. (2009) used principal components analysis to derive a multi-dimensional religiosity scale using 15 items from the World Values Survey (see Inglehart, 1997) which was negatively and (marginally) significantly associated with ultimatum game offer sizes among Malaysian and UK participants. In the study by Tan and Vogel (2008) on German University students, higher religiosity receivers were trusted more especially by fellow high-religiosity senders. Receivers of higher religiosity returned greater amounts and especially to more religious senders.

The results of Tan and Vogel suggest that religiosity can have an indirect effect as a social identity that generates ingroup favouritism. However, this is inconclusive in that religiosity differences in this study did not explain why senders trusted more religious receivers more. Alternatively the result could evidence statistical discrimination towards highly religious people to the extent that they are generally held to be trustworthier. Finally, in Chuah et al.'s (2014) prisoner's dilemma experiment, shared religious creed raised cooperation within a multi-cultural Malaysian student participant pool. In contrast, multi-dimensional religiosity as an independent variable in its own right did not explain cooperation. However, religiosity raised cooperation further when interacted with the shared creed dummy variable. This result suggests a further, again indirect effect of religiosity as an enhancer of ingroup bias based on shared religious affiliation. Alternatively, the result could reflect the greater general tendency of religious individuals to discriminate on the basis of different social identities including religious creed.

Let us now consolidate these results as behavioural patterns from the perspective of religious connectedness, as outlined in the introduction. First, individual religiosity can increase connectedness in three ways. First, the participation in ritual increases the duration and frequency of interactions between individuals. Second, increases in religious knowledge and indoctrination increases knowledge of others in the group, e.g. how they think they ought to behave (Tan, 2006). The latter relates to the access to relevant social category, and in turn the likelihood of using that social categories as stereotypes to guide behaviour such as trust (Tan and Vogel, 2008). Thirdly and indirectly, common beliefs and experiences engender familiarity and closeness, which then carry over to group identification and biases 
at the levels of similarity in religiosity (Tan and Vogel, 2008) or religious affiliation (Chuah et al., 2014). Such effects should weaken as religious connectedness weakens, via the above processes as well as a decreasing overlap in social networks. In the limit, we have interactions across group markers that are orthogonal to religion. If so, would individual religiosity lose its bite on discrimination?

\section{The experiment}

\subsection{Measuring trust and religion}

Following previous studies we used a trust game as a behavioural measure allowing for the expression of discrimination (e.g. Fershtman and Gneezy, 2001; Holm and Danielson, 2005; Falk and Zehnder, 2013). As shown in figure 1, we used a binary version of the trust game because it is cognitively less demanding on participants, so as to reduce biases from fatigue in view of the 88 games each participant had to play. The sender and the receiver begins each game with 200 points. We test two parameterisations of the trust game. In the first, namely the "low stake game", the sender decides whether or not to trust, i.e. to send 50 or 0 to the receiver. If the sender sends the money, the receiver receives three times this amount and decides whether or not to be trustworthy by returning 100 or 0 . In the second, i.e. the "high stake game", we increase the stakes by allowing the sender to send 150 or 0 to the receiver, and the receiver decides whether or not to return 300 or 0 .

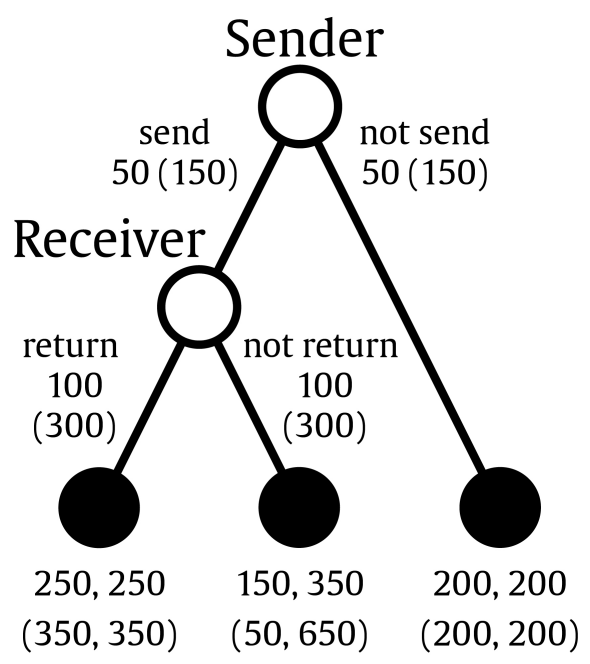

Figure 1: Actions and payoffs for the low (high) stake trust game used in the experiment. 
Assuming players are rational and money maximising, in equilibrium nobody sends any money. By backward induction, receivers will prefer more money to less and not return anything to the sender, i.e. not reciprocate. The sender anticipates this and prefers not to send anything to the receiver, i.e. not trust, because the payoff from withholding is higher than sending and not receiving anything in return. The subgame perfect equilibrium is that neither sender nor receiver sends any money. This forms the benchmark relative to which we can measure the trust and trustworthiness of senders and receivers, respectively. It follows that there is low (high) temptation for the receiver to send 0 , and this implies a low (high) stake for the sender in trusting the receiver. The two games allow us to test our hypotheses within a wider domain of stakes.

In order to obtain measures of discrimination, we administered the trust game under different social identity conditions using the strategy method (Selten, 1967). To keep sender and receiver tasks symmetric, in the experiment we allowed receivers to choose "return" or "not return" under the understanding that the decision only applies if the sender had chosen "send". In practice, the sender's decision would not influence payoffs in the game if the sender does not send any money. To make this explicit, we displayed games on the screen as extensive form representations consistent with this strategy method setup (see figure 2). In the first two rounds of the experiment, all senders and receivers stated their decision of whether to send or not to send without knowing the social identities of their co-participants. One round was for the high stake condition and the other the low stake condition, in counterbalanced orders across participants. We call these actions default actions.

In the other rounds that followed, participants stated their decision based on every possible co-participant's social identity type according to different social categories (see table 1). There were 88 rounds in total. Using religious affiliation as an example of a category, every participant was asked whether they would send or not send to co-participants of every religious affiliation (type) we provided, i.e. Buddhist, Christian, Hindu, Jewish, Muslim, other or none. This process was repeated for every type of every category, presented in random order after the tasks without social identity were performed. We call these actions conditional actions. Each category thus constitutes an experimental condition.

In each round where participants could base their decisions on the co-participants' social identities, they were provided with an additional endowment of 100 points from which they could spend an amount of their choice to increase the probability of implementing their conditional action instead of their default action. Each point increases the probability by $1 \%$, and each point unspent accrues as experimental payoffs. This incentive compatibly elicits their willingness to discriminate (WTD). 
When calculating experimental earnings, we applied the participant's stated WTD for the condition in concern to set the probability that the conditional action rather than the default action was to be used, and randomly determined subject to this probability.

As an example, consider a high stake game where a participant chooses to send 150 to co-participants of high religiosity, and 0 to other types of co-participants. Assume also that the default is to send 0. A WTD of 20 points means that if the participant is subsequently randomly matched with a high religiosity co-participant for the purpose of calculating experimental earnings, there is a $20 \%$ probability that the choice of sending 150 is implemented, and a complementary probability of $80 \%$ that the default action of sending 0 will be implemented. A WTD of 100 points means sending 150 to the high religiosity co-participant for sure, and sending 0 to a medium or low religiosity co-participant for sure. Higher WTD values increase the probability that discriminating decisions are used to determine earnings and therefore represent the decision maker's willingness to pay for social identity information to afford discriminating actions.

This method of eliciting WTD is novel and has two advantages. First, it experimentally models the costliness involved in discrimination activities, e.g. it takes time and effort to find out another person's religiousness or political inclination. This introduces an externally valid dimension to the test. In retrospect, observed decisions in previous experiments without this feature (e.g. Tan and Vogel (2008)) capture behaviour "as if" the participant confidently assumes or knows the coparticipant's social type. Second, the costliness of discrimination is in a way a disincentive to discriminate that mitigates demand effects in terms of discriminating actions, and in doing so incentive compatibly reveals the demand of the individual who despite of this cost goes for it. That said, we should not and do not try to remove all demand effects from the experiment, for we are interested in those germane to the act of discriminating on the basis of social identity-to which we can clearly attribute as the cause of action.

Figure 2 shows the experimental interface employed to elicit decisions. The interface shown in this example is asking participant 39, assigned to the sender role ("Person A") to make decisions in the religiosity category for a low stake game ("Round 4"). The game tree displays the actions and associated payoffs for participants in both roles. The dark shaded button indicates the benchmark decision this participant has already indicated previously, which cannot be changed ("SEND"). The participant must make trust decisions in the religiosity category by clicking on either the SEND or NOT SEND buttons for each possible co-participant religiosity type, namely "High", "Medium" and "Low" religiosity. The participant 


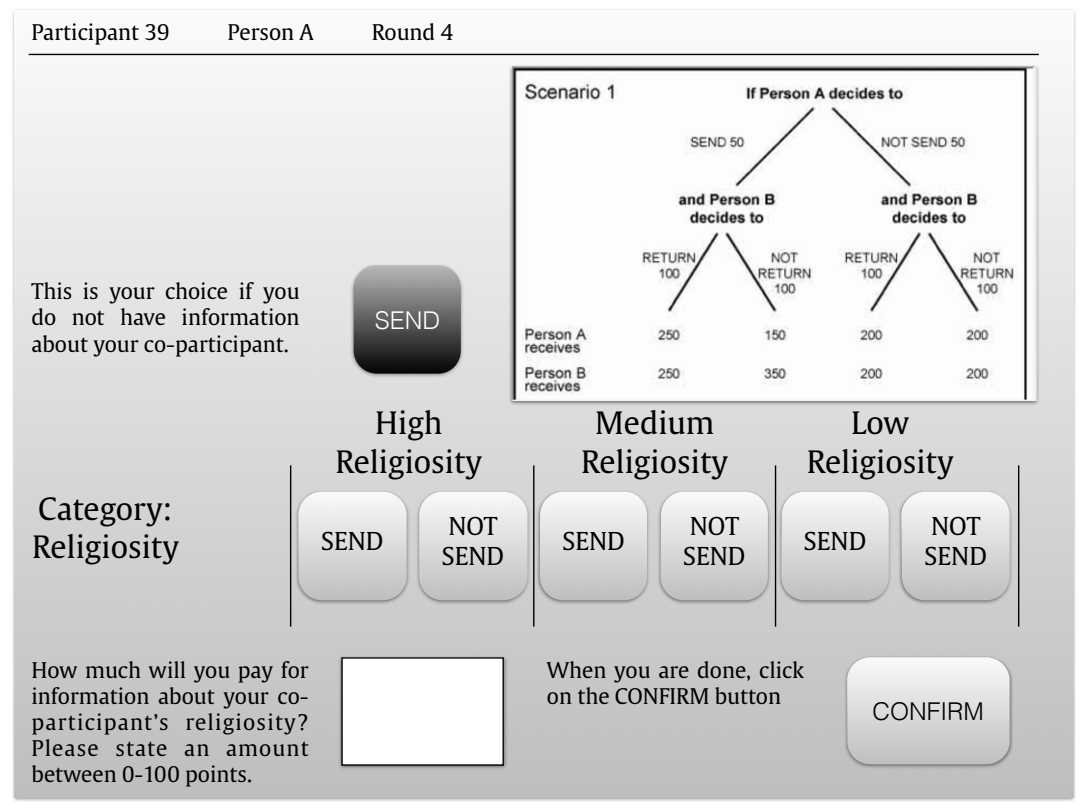

Figure 2: Experimental interface for the elicitation of trust game decisions for different social identity types and WTD. In this example, the category is religiosity.

then indicates what proportion of the 100 points to allocate towards implementing the relevant conditional choice, i.e. their stated WTD. Once all these decisions have been made, the participant clicks on CONFIRM to enter them and proceed to the next round, which involves a different category.

We administered a pen-and-paper questionnaire after the completion of the trust game task to collect additional measures. Beliefs were elicited as participants' expectations of co-participant actions in the trust game. Participants were asked (in their roles and for every possible value in every social identity category) to state the probability that such a type of co-participant would choose to send. Participants were paid depending on how close these beliefs were to true distribution of choices observed in the experiment, and payments were computed according to the quadratic scoring rule (Selten, 1998). We also recorded each participant's own demographic characteristics for each of the social identity categories in order to classify them in terms of the values for each category shown in table 1. Notably, we elicited individual religiosity according to the Glock and Stark (1965) dimensions using the denomination-robust 8-item instrument by Rohrbaugh and Jessor (1975) which yields our religiosity measure. It takes into consideration different dimensions of religion, namely belief, ritual, consequences, theology, and experience. It delivers an individual's overall score between 0 and 32 (see Hill and Hood, 1999). 


\begin{tabular}{||l|l|l||}
\hline \hline Condition & Social identity category & Types per category \\
\hline \hline 0 & None (benchmark) & \\
\hline 1 & Religious denomination & $\begin{array}{l}\text { Buddhist, Christian, Hindu, Jewish, Muslim, } \\
\text { Muslim, other, none }\end{array}$ \\
\hline 2 & Religiosity & High, medium, low \\
\hline 3 & Course & $\begin{array}{l}\text { Applied science, arts, business, economics, } \\
\text { pure science, social science, other }\end{array}$ \\
\hline 4 & Nationality & Chinese, Malaysian, UK, other \\
\hline 5 & Campus location & China, Malaysia, UK \\
\hline 6 & Ethnicity & $\begin{array}{l}\text { Black, Chinese, Indian, Malay, } \\
\text { Middle Eastern, White, other }\end{array}$ \\
\hline 7 & Political orientation & Left-wing, right-wing \\
\hline 8 & Voluntary participation & Active member, inactive member, not a member \\
\hline 9 & Gender & Male, female \\
\hline 10 & Age & $\leq 15$ years, 16-20, 21-25, 26-30, $\geq 31$ \\
\hline 11 & Birthday group & Even and odd-numbered calendar days \\
\hline \hline
\end{tabular}

Table 1: Social identity categories and types used in the experiment with resulting experimental conditions.

\subsection{Hypotheses}

Piecing together the mosaic of results given by the literature from the perspective of religious identity and connectedness, we shall use our experiment to test the following four hypotheses. These explanations of behaviour are not mutually exclusive and could operate in concert, potentially coexisting or reinforcing each other. We cater for these possibilities in the analysis.

Hypothesis 1 (Statistical discrimination). Senders generally believe that receivers of higher religiosity are trustworthier, and statistically discriminate by being more likely to trust them more than receivers of no or lower religiosity.

The first possibility for the expression of religiosity in terms of economic behaviour is statistical discrimination (e.g. Anderson et al., 2006) when a person's social identity contains information regarding particular behaviour tendencies that can feed into strategic considerations, e.g. beliefs of trustworthiness. Statistical discrimination in the trust game applies only to senders, as they must anticipate the likelihood that receivers will fulfill or abuse their trust if invested. Tenets such as charity, neighbourly love and the Golden Rule are common to all religions and may confer a trustworthy reputation on religious people (e.g. Spilka et al., 2003, p. 172). If statistical discrimination based on religiosity is present in the current experiment, all senders regardless of their own religiosity should be more 
likely to behave trustingly towards receivers of greater religiosity levels. Senders would therefore be more likely to send to receivers of higher religiosity, compared to receivers of lower religiosity, and this effect should increase with the sender's religiosity.

Hypothesis 2 (Ingroup love). Religiously affiliated senders are more likely to invest trust in receivers who are affiliated to the same religion, relative to receivers who are not religiously affiliated or affiliated to a different religion. This effect increases with the sender's religiosity.

Religiosity is a fundamental measure of religiousness as an individual. It might vary across religious affiliations. In turn, it weakens connectedness, e.g. from variances in religious doctrine and prescriptions for behaviour. Further, it is arguably more subtle than religious affiliation, which may serve mainly as a badge of membership. It follows that while religiosity might be a weaker marker of religious connectedness, it could serve to amplify discrimination effects based on religious affiliation, which increases the salience of religious categories as social markers.

Thus, the degree to which people exhibit biased intergroup behaviour is related to the strength of their identification with the group concerned, and in turn increases cooperation through stronger social preferences (Farnham et al., 1999; Chen and Xin, 2009). In particular, greater discrimination can result from a loss in (implicit) self-esteem in people who highly identify with a particular social group that is undergoing a threat, i.e. a perceived negative evaluation by others (Smurda et al., 2006). In the current context this hypothesis suggests that greater trust in co-participants of the same religious group is relatively stronger in more religious participants in either role. Such effects are reinforced by individual religiosity, which embodies closeness nurtured through joint participation in activities. This, in turn, increases trust by increasing religious connectedness through commitment to the creed, i.e. ingroup membership. Religiously affiliated senders would therefore be more likely to send to receivers belonging to the same creed, compared to receivers who are atheists of followers of other creeds, and this effect should increase with the sender's religiosity.

Hypothesis 3 (Religious affinity). Religiously affiliated senders are more likely to invest trust in receivers who are affiliated to some-regardless of which-religion. This effect increases with the sender's religiosity.

The third possibility we test is that people consider their religious affiliation or religiosity a pertinent social identity and exhibit biased intergroup behaviour (i.e. 
ingroup favouritism or outgroup prejudice) towards others depending on whether or not they are also religiously affiliated to some creed-irrespective of whether or not it is the same one. For example, former Prime Minister of the United Kingdom Tony Blair articulated this thinking publicly at the Westminster Faith Debate on "Religion in Public Life" held in London on 24 July 2012, "I find a connection with people who are of faith, even though they're of a different faith to my own, precisely because there is a certain space, philosophically and emotionally, you can congregate around." Put differently, this weakens the religious connectedness relative to that between individuals of the same creed. That said, religious affinity does not extend to group membership, and its effect should be relatively weaker. A religious affiliate would thus be more likely to send in the trust game to another who is affiliated to some religion-regardless of whether or not it is the same creed, and this effect should increase with the sender's religiosity.

Hypothesis 4 (General prejudice). Religious senders are generally more biased, such that they are more likely to send to receivers with the same non-religious social identity.

Finally, since the middle of the last century (Adorno et al., 1950; Allport, 1954), psychological studies have repeatedly identified links between individual religiousness and attitudes of prejudice. Such prejudice is counter to religious teachings of charity, forgiveness, love and compassion. This link is complex and dependent on a number of other factors including religious orientation, social desirability and doctrinal attitudes towards particular out-groups (Spilka et al., 2003, chapter 14). Links between religiosity and prejudicial attitudes have been demonstrated repeatedly (Allport and Ross, 1967; Altemeyer and Hunsberger, 1992; Hunsberger and Jackson, 2005; Hunsberger, 1996; Jackson and Hunsberger, 1999). We consider the possibility that religious people are generally more disriminating in the context with the weakest religious connectedness. If this holds, we should find that senders of higher religiosity have greater WTD across all social identity categories or overall. We should also find that religious senders are more likely to send to the "ingroup" based even on non-religious categories. In experimental terms, we are thus testing for the effect of religion on the individual's inherent disposition to discriminate.

\footnotetext{
${ }^{2}$ Tony Blair is founding patron of the Tony Blair Faith Foundation and recently stepped down as the Special Envoy of the Middle East Quartet. The quote was extracted from http://faithdebates.org.uk/debates/2012-debates/religion-and-public-life/religionpublic-tony-blair-rowan-williams/ (2012).
} 


\subsection{Procedure}

We ran the experiment at the China, Malaysia, and UK campuses of the University of Nottingham. All campuses use English as the medium of instruction, and share common degree structures and syllabi. This participant pool affords high direct comparability of data collected from these diverse cultures. The cultural diversity of our sample widens the study's domain of validity. Such diversity increases the number of subjects of each social identity type. Thus, there is a much larger number of ingroup and outgroup combinations, which we shall also use to test for the cultural sensitivity or robustness of our findings. We used a computerised interface in English with 545 student volunteers (273 senders and 272 receivers) recruited by poster and e-mail announcements for 90-minute sessions of 20-40 participants. The experimental software was programmed in Visual Basic 6, and the computerised text was in English.

Our experiment followed the standards of cross-cultural experimental economics (Roth et al., 1991; Herrmann et al., 2008). Instructions, comprehension quiz questions, belief elicitation and demographic questionnaire were provided in the respective local languages. The English version was always available to participants in China and Malaysia on demand. The original English version was first translated to Chinese and Malay, and then back translated to English to check for consistency. Any inconsistencies were resolved in consensus with the co-authors on this project. Translations were performed by three people who are not co-authors on the project, but are native speakers of Chinese or Bahasa Melayu and English. All of them have professionally worked in the respective two languages. The English version of the experimental instructions are found in the online appendix.

Participants were randomly assigned to either the sender or receiver role throughout the experiment, and made trust game decisions first for socially unidentified co-participants and then for each of the social identity categories and types as described (see table 1), for both the low and high stake conditions, in individualised random order. After all experimental sessions were completed, participants were randomly matched experiment-wide across the three locations, and one social identity category was selected randomly to determine earnings. The participants' total earnings were the points from the game, those remaining from the WTD endowment, and payments depending on the accuracy of their beliefs in one randomlychosen belief task, with the answer compared to the statistical return rate of the sample for the type of participant. We paid participants at the rates of Renminbi (RMB) 0.20, Ringgit Malaysia (RM) 0.08 and Pounds Sterling (£) 0.04 per point earned plus a show-up fee (RMB 25, RM 10 or $£ 5$ respectively). Earnings were collected a week after the final session to allow for experiment-wide participant 
matching over the three locations. We paid participants in the three locations RMB 63.68, RM 28.66 and $£ 14.65$ on average. Each session lasted approximately $1.5 \mathrm{~h}$. The exchange rate between the three currencies we used was determined using the Big Mac Index published annually by The Economist magazine.

\section{Results}

Before testing our four hypotheses we look at some basic features of the data. Appendix A1 provides the distributions of participant types of each category across the three locations, and a summary of mean WTD, beliefs and actions across conditions and types by roles and locations. Religiosity scores ranged from 0-30 and the average was 11.86. The mean age was 20.48 (standard error of 0.008). In ethnic and religious terms, China is most homogeneous with 162 ethnic Chinese, 134 atheists and 25 Buddhists, out of 164 participants in total. Malaysia and UK are relatively heterogeneous, with Chinese (106) and White (115) as majority ethnicities, and Buddhists (61) and Christians (56) as majority religions, out of 187 and 194 participants in total, respectively. In Malaysia and UK, the non-majority religions are all represented, apart from no Jewish participant in the Malaysia subsample. In the high (low) stake baseline games where decisions could not be conditioned on the social identity of co-participants, $38.1 \%$ (56.0\%) of senders chose to trust, and $27.9 \%$ (43.0\%) of receivers chose to reciprocate. Further details may be found in appendix A1.

\subsection{Preliminaries}

We first check for independent effects of religiosity on trust, to confirm the result from previous studies that forms our departure point. Our measure of religiosity is $R E L I$, which is the mean centered to avoid multi-collinearity in our regressions below, following Marquardt (1980). There is no significant difference in the religiosity of senders who trust and those who do not in both the high (t-test, $p=0.780$, 2 -tailed henceforth) and in the low stake condition $(p=0.758)$, or for receivers in either the high $(p=0.775)$ or low condition $(p=0.886)$. To corroborate, individual level random effects binary logit regressions controlling for beliefs, stake and gender show that religiosity does not significantly influence trust and trustworthiness ( $p=0.921$ and $p=0.375$, respectively; see appendix A1 for details). As there is no evidence for an independent influence of religiosity on trust and trustworthiness.

Senders spent an average of 21.4 and receivers 22.0 out of a hundred points to increase the probability of implementing their conditional actions (i.e. WTD) in the religious affiliation condition, where actions could be conditioned on the 
co-participant's religious denomination. WTD rises with one's religiosity level at 19.3, 21.2, and 30.9 for low, medium and high religiosity, respectively. Senders spent an average of 20.9 and receivers 20.0 points on WTD in the religiosity condition, where actions could be conditioned on the co-participants level of religiousness. WTD rises with one's religiosity level at 19.8, 19.9 and 26.0 for low, medium and high religiosity, respectively. The same pattern holds for receivers at 19.5, 23.0, and 29.6 (18.7, 21.8 and 21.5), respectively, for low, medium and high religiosity. Further, $58.6 \%(50.7 \%)$ of senders and $48.2 \%$ (43.9\%) of receivers, discriminate on the basis of religious affiliation (religiosity) in the sense that they choose different conditional actions for different types of co-participants. ${ }^{3}$ With information of religious affiliation (religiosity), $23 \%(22.7 \%)$ of behaviour differs from that in the baseline: $9.2 \%(10.1 \%)$ increase and $13.8 \%(12.7 \%)$ decrease trust. As described in section 3.2, this widely observed discrimination can take a number of forms as expressed in our four hypotheses, which we test next.

To control for and to test the interplay of effects from multiple variables and their interactions, we use multivariate analysis. Our regressions include individuallevel random effects to control for the potential non-independence of multiple observations per individual. We never provided participants with feedback between choices so there is independence between observations across participants. We always control for low and high stake conditions $(S T A K E=1$ for the high stake condition and $=0$ for the low stake condition), and for own gender (FEMALE $=1$ for females and $=0$ for males) due to known gender effects on trust game behavior (Croson and Buchan, 1999). Our regressions always include individual religiosity RELI. Results are robust to the inclusion of $W T D$ or dummy variables for location (these alternative models are reported in online appendix OA3).

\subsection{Statistical discrimination}

Statistical discrimination implies that senders believe that some types of receivers are trustworthier than others. These stated beliefs are given by the dependent variable $B E L I E F=0$ to 1 . According to hypothesis 1 , a sender, irrespective of her own social identity, uses the receiver's religiosity to form an expectation of their trustworthiness. Participants should therefore be willing to pay more than in identity conditions unrelated to any possible statistical discrimination. Our control

\footnotetext{
${ }^{3}$ For the Malaysia and UK subsamples, we find no significant difference between trust in the baseline and all information conditions overall. As for the Chinese subsample, there is lower trust in the age, religion, religiosity, ethnicity, education, political orientation and voluntary participation conditions. Welfare is lower if we assume a uniform distribution of types. see our t-tests in the online appendix OA1.
} 
condition is a "birthday" category where actions were conditioned on whether the co-participant was born on an even or odd day of the month. There, mean WTD is 17.7 and its confidence interval is 16.1-19.2. The mean WTDs of the religious affiliation and religiosity categories are 21.4 and 20.9, respectively, i.e. outside the interval. We also examine how beliefs regarding the trustworthiness of receivers vary with the decision maker's religiosity using a religiosity level variable $R L E V$. This variable was used in the experiment to elicit participants' beliefs and actions contingent on the co-participant's low $(R L E V=0$ if religiosity questionnaire score is $0-10)$, medium $(R L E V=1$ if score is 11-20) and high ( $R L E V=2$ if score is above 20) religiosity. ${ }^{4}$ We test this effect on senders across all religious affiliations. Further, to test if being of a similar religiosity level reinforces statistical discrimination, we interact $R L E V$ with $R E L I$.

Senders' beliefs that low, medium, and high religiosity receivers would act trustworthily are $0.33,0.41$ and 0.43 respectively, pooled over both stake conditions. Average beliefs and actions are shown broken down by participants' own religiosity levels in figure 3. Senders of diverse religiosities believe that receivers of higher religiosity are more likely to return (top left figure), and are more likely to send to them (top right figure). Receivers of diverse religiosities believe that senders of higher religiosity are more likely to trust (bottom left figure), and are as likely to return to senders of different religiosity levels.

Regression analysis confirms that more religious people are trusted more by people across different levels of religiosity, as the $R L E V$ coefficient is positive and significant in models 1-3. This result holds overall, for people without or with religious affiliation, as demonstrated by the regressions on the pooled sample (model 1) and subsamples disaggregated by people without (model 2) or with (model 3) religious affiliation. Further, the statistically insignificant $R L E V \times R E L I$ coefficient in model 4 shows that senders of different levels of religiosity are as likely to believe that receivers of high religiosity are trustworthier, confirming that statistical discrimination holds across senders irrespective of religiosity.

Next, we test if religious people are indeed trusted more. Define $a_{\text {type }}$ as the action that is conditionally chosen for the corresponding type of co-participant (see the variety of types per category in table 1). We do not use the conditional action $a_{\text {type }}(=1$ if send and 0 otherwise) as dependent variable as it is not incentive

\footnotetext{
${ }^{4}$ The reason for this variable is that eliciting such conditional responses on the basis of every possible value of co-participant religiosity score is impractical. We also use RLEV in figure 3 merely for the purpose of clearer exposition to break down the beliefs and decisions of participants according to their own level of religiosity.
} 

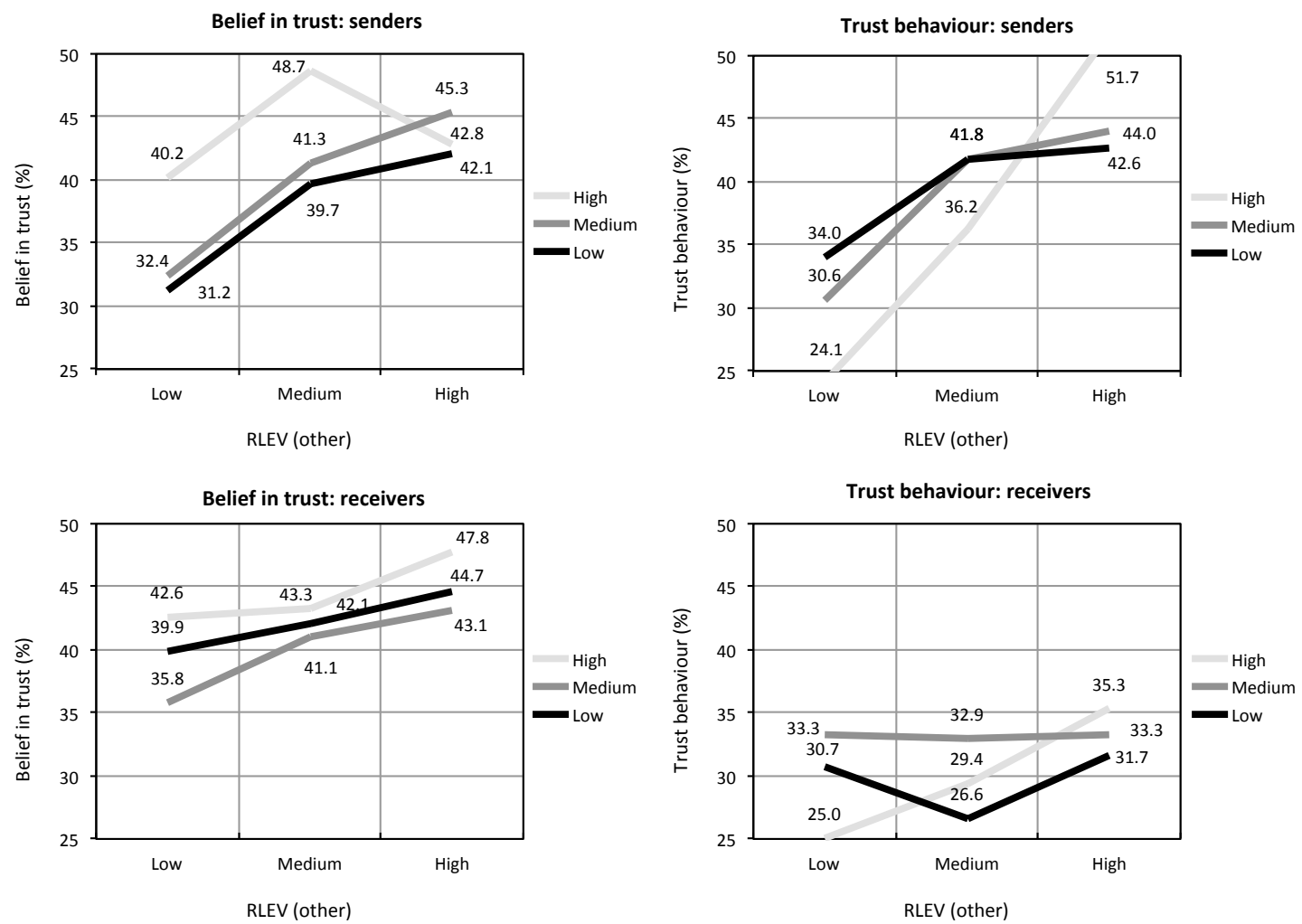

Figure 3: Senders' and receivers' beliefs and acts of trust and reciprocity (\%) depending on co-participant level of religiosity (RLEV (other)) pooled for both stake conditions. Each graph represents participants grouped by their own religiosity level (RLEV (own)). The standard errors of the means ranged from 0.64 to 3.80 but are not displayed for the sake of presentational clarity. 


\begin{tabular}{lcccccc}
\hline \hline & $(1)$ & $(2)$ & $(3)$ & $(4)$ & $(5)$ & $(6)$ \\
& BELIEF & BELIEF & BELIEF & BELIEF & WSEND & WSEND \\
& All & Atheists & Affiliates & All & All & All \\
\hline STAKE & $-0.044^{* * *}$ & $-0.067^{* * *}$ & -0.022 & $-0.044^{* * *}$ & $-0.166^{* * *}$ & $-0.151^{* * *}$ \\
& $(0.010)$ & $(0.014)$ & $(0.015)$ & $(0.010)$ & $(0.018)$ & $(0.017)$ \\
FEMALE & -0.037 & -0.030 & -0.042 & -0.037 & 0.059 & $0.072^{* *}$ \\
& $(0.023)$ & $(0.033)$ & $(0.033)$ & $(0.023)$ & $(0.039)$ & $(0.037)$ \\
RELI & $0.027^{*}$ & -0.004 & $0.053^{* *}$ & $0.052^{* *}$ & 0.007 & -0.002 \\
RLEV & $(0.014)$ & $(0.030)$ & $(0.021)$ & $(0.021)$ & $(0.024)$ & $(0.023)$ \\
& $0.054^{* * *}$ & $0.051^{* * *}$ & $0.057^{* * *}$ & $0.053^{* * *}$ & $0.020^{*}$ & 0.003 \\
RLEV by RELI & $(0.006)$ & $(0.009)$ & $(0.009)$ & $(0.006)$ & $(0.011)$ & $(0.011)$ \\
BELIEF & & & -0.012 & & \\
CONSTANT & $0.320^{* * *}$ & $0.329^{* * *}$ & $0.287^{* * *}$ & $0.320^{* * *}$ & $0.475^{* * *}$ & $0.369^{* * *}$ \\
& $(0.021)$ & $(0.029)$ & $(0.033)$ & $(0.021)$ & $(0.035)$ & $(0.036)$ \\
\hline Overall r ${ }^{2}$ & 0.044 & 0.045 & 0.058 & 0.045 & 0.039 & 0.095 \\
N & 1602 & 798 & 804 & 1602 & 1602 & 1602 \\
\hline \hline
\end{tabular}

Table 2: Random effects regressions to test for statistical discrimination. The data is from the religiosity condition. Models 1, 4, 5 and 6 are based on data from all senders, 2 from senders without religious affiliation, and 3 from senders with religious affiliation. Dependent variable $B E L I E F=$ stated probability of receiver returning, and $W S E N D=W T D \times a_{\text {type }}+(1-$ $W T D) \times a_{\text {default }}$, where $W T D=$ stated willingness to discriminate, $a_{\text {type }}=$ the conditional action chosen for a certain receiver type, and $a_{\text {default }}=$ the default action. $R L E V$ in this table refers to the co-participant's religiosity level. Random effects are at the participant level. Significance levels are denoted by ${ }^{* * *}$ for $p<0.01$, ${ }^{* *}$ for $p<0.05$, and ${ }^{*}$ for $p<0.1$. Standard errors are in parentheses. 
compatible. This is because the conditional actions of participants with $W T D=0$ will never be implemented and therefore carry no weight, while the default action $a_{\text {default }}$ should carry full weight. ${ }^{5}$ The dependent variable we use is the weighted average of senders' actions $W S E N D=W T D \times a_{\text {type }}+(1-W T D) \times a_{\text {default }}$. $W R E T U R N$ is the weighted average of receivers' actions and calculated accordingly. Model 5 shows a marginally significant $R L E V$ effect in the pooled sample, while model 6 shows that there this becomes insignificant once we control for beliefs. Models 5 and 6 show that trust actions depend on religiosity of the co-participant and beliefs of the co-participant's trustworthiness. These beliefs are consistent with actions, and beliefs are themselves increasing in religiosity. This supports the statistical discrimination hypothesis. ${ }^{6}$

Result 1 (Statistical discrimination). Senders of all levels of religiosity believe that receivers of higher religiosity are trustworthier, and behave consistently with this belief by trusting them more.

\subsection{Ingroup love}

According to hypothesis 2, higher religiosity strengthens the identification of participants with the religious group they are affiliated to, and thereby amplifies ingroup biases based on affiliation. We use $W S E N D$ as the dependent variable. To test for ingroup biases, we define a dummy variable INGROUP that takes on the value of 1 when participants are making decisions conditional on participants that are of the same type as them for the category in concern. In this case of ingroup biases in religious affiliation, INGROUP $=1$ when co-participants are of the same religious affiliation, and $=0$ otherwise. When people have information about others, they use it to guide their actions. In turn, this feeds into behaviour. Thus, our models of WSEND include BELIEF to control for statistical discrimination. However, beliefs do not necessarily explain behaviour completely, for taste-based discrimination can also play a role. ${ }^{7}$ Thus, by controlling for the effect of statistical discrimination with BELIEF, INGROUP is a measure for taste-based discrimination, such that remaining ingroup effects are attributable to it. We include the mean centered measure of individual religiosity $R E L I$ as well as the interaction

\footnotetext{
${ }^{5}$ That said, our results are robust to adopting $a_{\text {type }}$ as the alternative dependent variable.

${ }^{6}$ The results of Models $1,2,3,5$ and 6 are robust to the inclusion of interaction term of $R L E V \times R E L I$.

${ }^{7}$ Also because of the taste-based motive to acquire information, beliefs do not necessarily positively correlate with WTD.
} 


\begin{tabular}{|c|c|c|c|c|c|c|c|}
\hline & $\begin{array}{c}(7) \\
W S E N D \\
\text { All }\end{array}$ & $\begin{array}{c}(8) \\
W S E N D \\
\text { Atheists }\end{array}$ & $\begin{array}{c}(9) \\
W S E N D \\
\text { Affiliates }\end{array}$ & $\begin{array}{c}\left(7^{\prime}\right) \\
W S E N D \\
\text { All }\end{array}$ & $\begin{array}{c}\left.8^{\prime}\right) \\
W S E N D \\
\text { Atheists }\end{array}$ & $\begin{array}{c}\left(9^{\prime}\right) \\
W S E N D \\
\text { Affiliates }\end{array}$ & $\begin{array}{c}(10) \\
W R E T U R N \\
\text { All }\end{array}$ \\
\hline BELIEF & $\begin{array}{c}0.134^{* * *} \\
(0.027)\end{array}$ & $\begin{array}{c}0.135^{* * *} \\
(0.039)\end{array}$ & $\begin{array}{c}0.125^{* * *} \\
(0.039)\end{array}$ & $\begin{array}{c}0.139^{* * *} \\
(0.029)\end{array}$ & $\begin{array}{c}0.171^{* * *} \\
(0.041)\end{array}$ & $\begin{array}{c}0.110^{* * *} \\
(0.041)\end{array}$ & $\begin{array}{c}0.070^{* * *} \\
(0.023)\end{array}$ \\
\hline$S T A K E$ & $\begin{array}{c}-0.152^{* * *} \\
(0.011)\end{array}$ & $\begin{array}{c}-0.157^{* * *} \\
(0.015)\end{array}$ & $\begin{array}{c}-0.146^{* * *} \\
(0.016)\end{array}$ & $\begin{array}{c}-0.141^{* * *} \\
(0.011)\end{array}$ & $\begin{array}{c}-0.138^{* * *} \\
(0.015)\end{array}$ & $\begin{array}{c}-0.142^{* * *} \\
(0.017)\end{array}$ & $\begin{array}{c}-0.109^{* * *} \\
(0.009)\end{array}$ \\
\hline FEMALE & $\begin{array}{c}0.060 \\
(0.038)\end{array}$ & $\begin{array}{c}0.060 \\
(0.057)\end{array}$ & $\begin{array}{c}0.074 \\
(0.052)\end{array}$ & $\begin{array}{c}0.048 \\
(0.037)\end{array}$ & $\begin{array}{c}0.041 \\
(0.057)\end{array}$ & $\begin{array}{c}0.064 \\
(0.051)\end{array}$ & $\begin{array}{l}-0.017 \\
(0.043)\end{array}$ \\
\hline$R E L I$ & $\begin{array}{c}0.000 \\
(0.024)\end{array}$ & $\begin{array}{c}0.017 \\
(0.053)\end{array}$ & $\begin{array}{c}0.017 \\
(0.033)\end{array}$ & $\begin{array}{l}-0.007 \\
(0.024)\end{array}$ & $\begin{array}{c}0.013 \\
(0.052)\end{array}$ & $\begin{array}{l}-0.004 \\
(0.033)\end{array}$ & $\begin{array}{c}-0.052^{* *} \\
(0.026)\end{array}$ \\
\hline INGROUP & $\begin{array}{c}0.048^{* * *} \\
(0.016)\end{array}$ & $\begin{array}{c}0.022 \\
(0.028)\end{array}$ & $\begin{array}{l}0.061^{* *} \\
(0.026)\end{array}$ & $\begin{array}{c}0.043^{* * *} \\
(0.016)\end{array}$ & $\begin{array}{l}0.050^{*} \\
(0.028)\end{array}$ & $\begin{array}{c}0.040 \\
(0.027)\end{array}$ & $\begin{array}{l}0.024^{*} \\
(0.013)\end{array}$ \\
\hline $\begin{array}{l}\text { INGROUP } \\
\text { by RELI }\end{array}$ & $\begin{array}{l}0.037^{*} \\
(0.020)\end{array}$ & $\begin{array}{c}0.008 \\
(0.040)\end{array}$ & $\begin{array}{c}0.034 \\
(0.029)\end{array}$ & $\begin{array}{c}0.006 \\
(0.020)\end{array}$ & $\begin{array}{c}0.016 \\
(0.041)\end{array}$ & $\begin{array}{c}0.006 \\
(0.031)\end{array}$ & $\begin{array}{c}0.014 \\
(0.016)\end{array}$ \\
\hline CONSTANT & $\begin{array}{c}0.452^{* * *} \\
(0.029)\end{array}$ & $\begin{array}{c}0.480^{* * *} \\
(0.044)\end{array}$ & $\begin{array}{c}0.421^{* * *} \\
(0.044)\end{array}$ & $\begin{array}{c}0.452^{* * *} \\
(0.028)\end{array}$ & $\begin{array}{c}0.461^{* * *} \\
(0.044)\end{array}$ & $\begin{array}{c}0.444^{* * *} \\
(0.044)\end{array}$ & $\begin{array}{c}0.381^{* * *} \\
(0.029)\end{array}$ \\
\hline $\begin{array}{l}\text { Overall } r^{2} \\
N\end{array}$ & $\begin{array}{l}0.055 \\
3730\end{array}$ & $\begin{array}{c}0.063 \\
1862\end{array}$ & $\begin{array}{c}0.050 \\
1868\end{array}$ & $\begin{array}{l}0.046 \\
3728\end{array}$ & $\begin{array}{c}0.061 \\
1859\end{array}$ & $\begin{array}{c}0.038 \\
1869\end{array}$ & $\begin{array}{l}0.035 \\
3638\end{array}$ \\
\hline
\end{tabular}

Table 3: Random effects regressions to test for ingroup love. Models 7, 8, 9 and 10 are on data from the religious affiliation condition. Models 7'-9' analyse data from the ethnicity condition. Models 7 and $7^{\prime}$ are based on data from all senders, 8 and $8^{\prime}$ from senders without religious affiliation, 9 and 9' from senders with religious affiliation, and 10 from all receivers. The dependent variable for senders is $W S E N D=W T D \times a_{\text {type }}+(1-W T D) \times a_{\text {default }}$, where $W T D=$ stated willingness to discriminate, $a_{\text {type }}=$ the conditional action chosen for a certain receiver type, and $a_{\text {default }}=$ the default action. The dependent variable for receivers is WRETURN, and computed as such. Random effects are at the participant level. Significance levels are denoted by ${ }^{* * *}$ for $p<0.01$, ** for $p<0.05$, and $*$ for $p<0.1$. Standard errors are in parentheses. 
term INGROUP $\times$ RELI, which tests if ingroup biases are strengthened by the decision maker's religiosity.

Tests are performed on data from the religious affiliation condition rather than the religiosity condition where there is no clear sense of group membership. Note that participants were not told their own religiosity level according to our survey measure nor asked to state their perception of their own religiosity in absolute terms or relative to other participants. Figure 4 shows the percentage change in trust actions in $W S E N D$ conditional on the receiver's religious affiliation, relative to the baseline where decisions are made unconditionally. In UK and Malaysia, where most participants have religious affiliations, we observe increases in trust for the ingroup relative to the baseline, i.e. ingroup favouritism. In China, where most participants are atheists, we observe decreases in trust for the outgroup relative to the baseline, i.e. outgroup prejudice. We scrutinise this econometrically.

Referring to table 3, model 7 shows that senders are more trusting towards those of the same religious affiliation (INGROUP is positive and significant) and this effect increases with one's religiosity (INGROUP $\times R E L I$ is positive and marginally significant). The figure in appendix A3 shows that ingroups are consistently trusted more than outgroups by people across different religions. This finding is also robust to contextual differences across groups and societies. ${ }^{8}$ This ingroup effect does not hold for atheists but for religious affiliates (see models 8 and 9 , respectively). We run the same tests on receivers and find only a marginally significant positive INGROUP effect on WRETURN of the pooled data (see model 10), which corroborates the taste-based discrimination interpretation. Thus, we find support for hypothesis $2 .^{9}$

We also consider the possibility that religious affiliation serves as a proxy for ethnicity and vice versa. To investigate this, we analyse actions conditional on ethnicity. Regressions similar to models 7-9 on data from the ethnicity condition (models 7'-9') show significant ethnic biases (INGROUP is significant in model $\left.7^{\prime}\right)$. This effect is driven by atheists, as INGROUP is significant for participants without religious affiliation (model 8') but not for participants with religious affiliation (model 9'). If religious affiliation is used as a proxy for ethnicity, and it is

\footnotetext{
${ }^{8}$ Members of majorities and minorities of homogeneous (China) and heterogeneous (Malaysia and UK) societies consistently trust the ingroup more. Further, participants residing in more heterogeneous societies intermingle with more diverse people, and this might influence the nature of group biases, but we find that patterns of discrimination are alike. Details are provided in online appendix OA4.

${ }^{9}$ The results of models $7-10$ are robust to the exclusion of BELIEF.
} 

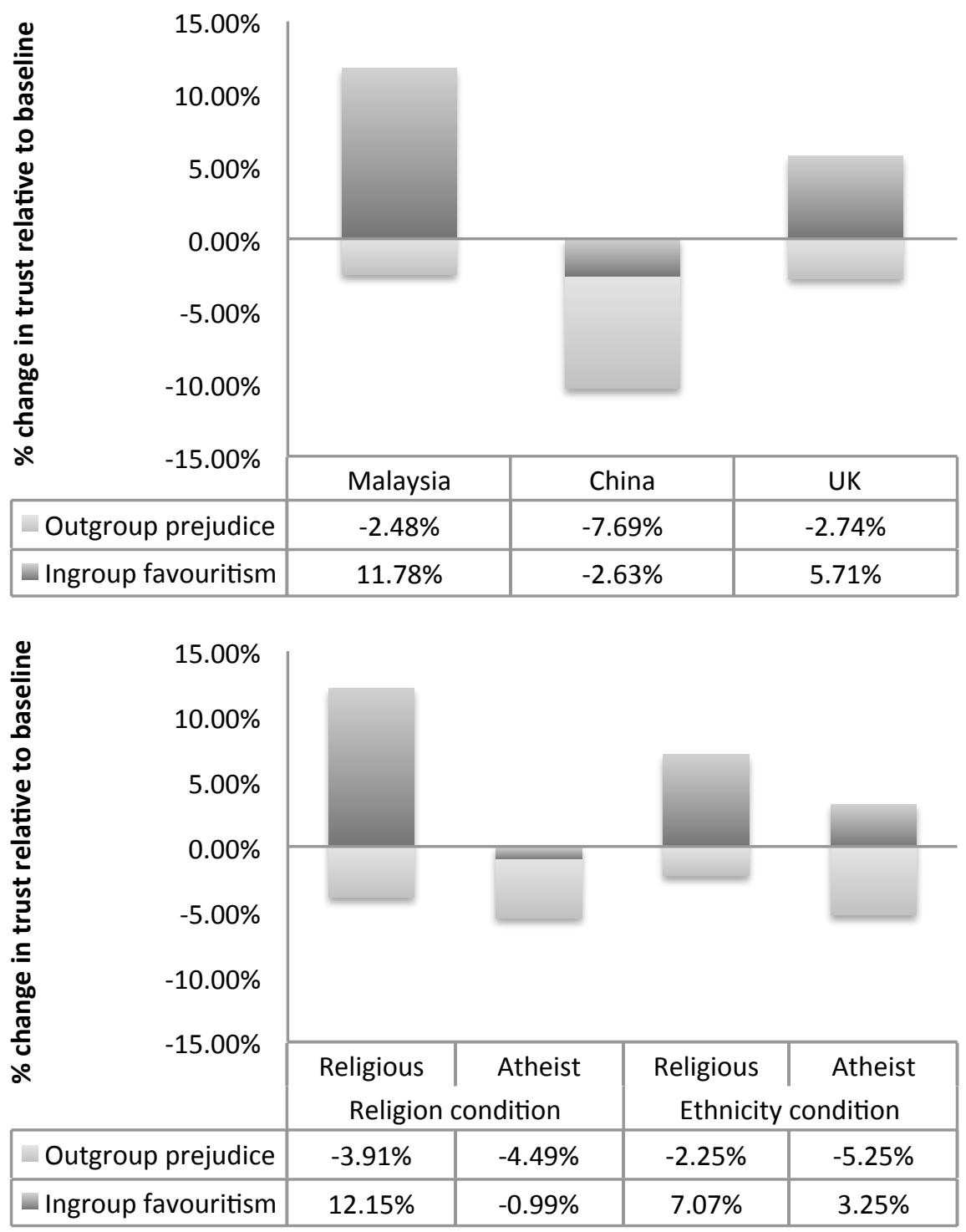

Figure 4: Senders' change in trust, relative to the baseline and as a percentage of trust in the baseline, when faced with an ingroup or outgroup co-participant. The top figure shows the change in trust observed in each campus. The bottom figure shows this for religious participants or atheists in the religious affiliation or ethnicity conditions (bottom). 


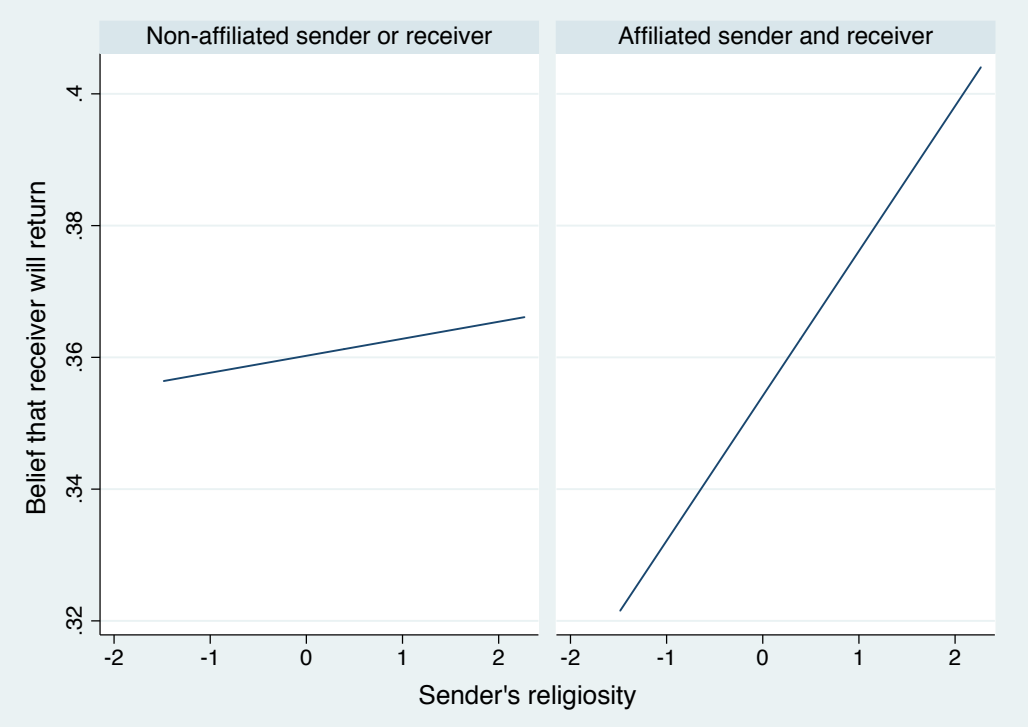

Figure 5: Plot of linear fit for senders' beliefs and religiosities. Senders' beliefs that receivers will return increase with sender religiosity if both participants are religiously affiliated (right), but not if even one of the two are not religiously affiliated (left).

\footnotetext{
${ }^{10}$ We also test this on campus and nationality, but find no significant biases (see online appendix OA2).

${ }^{11}$ The relative impact of ingroup favouritism vis a vis outgroup prejudice can be captured by a comparison of conditional ingroup and outgroup data to unconditional data. Relative to the baseline, the ingroup is trusted more in Malaysia and UK, and in China the outgroup is trusted less.
} 


\begin{tabular}{lcccccc}
\hline \hline & $(11)$ & $(12)$ & $(13)$ & $(14)$ & $(15)$ & $(16)$ \\
& BELIEF & WSEND & BELIEF & BELIEF & BELIEF & WSEND \\
& All & All & All & Atheists & Affiliates & All \\
\hline STAKE & $-0.061^{* * *}$ & $-0.152^{* * *}$ & $-0.061^{* * *}$ & $-0.089^{* * *}$ & $-0.033^{* * *}$ & $-0.159^{* * *}$ \\
& $(0.006)$ & $(0.011)$ & $(0.006)$ & $(0.009)$ & $(0.009)$ & $(0.011)$ \\
FEMALE & -0.020 & 0.062 & -0.019 & -0.009 & -0.006 & 0.058 \\
& $(0.023)$ & $(0.038)$ & $(0.023)$ & $(0.033)$ & $(0.033)$ & $(0.039)$ \\
RELI & -0.002 & 0.002 & -0.019 & 0.037 & -0.011 & -0.004 \\
& $(0.015)$ & $(0.025)$ & $(0.016)$ & $(0.031)$ & $(0.026)$ & $(0.028)$ \\
INGROUP & $-0.026^{* * *}$ & $0.049^{* * *}$ & $-0.026^{* * *}$ & $-0.046^{* * *}$ & -0.024 & $0.045^{* * *}$ \\
& $(0.009)$ & $(0.016)$ & $(0.009)$ & $(0.016)$ & $(0.015)$ & $(0.016)$ \\
INGROUP & -0.007 & $0.038^{*}$ & -0.010 & $-0.041^{*}$ & -0.004 & $0.036^{*}$ \\
by RELI & $(0.012)$ & $(0.020)$ & $(0.012)$ & $(0.024)$ & $(0.018)$ & $(0.020)$ \\
AFFILIATE & $0.051^{* * *}$ & -0.008 & $0.039^{* * *}$ & & $0.051^{* * *}$ & -0.005 \\
BELIEF & $(0.012)$ & $(0.020)$ & $(0.013)$ & & $(0.015)$ & $(0.022)$ \\
AFFILIATE & & $0.134^{* * *}$ & & & & \\
by RELI & & $(0.027)$ & & & $0.034^{*}$ & 0.013 \\
CONSTANT & $0.382^{* * *}$ & $0.455^{* * *}$ & $0.380^{* * *}$ & $0.436^{* * *}$ & $0.326^{* * *}$ & $0.506^{* * *}$ \\
& $(0.017)$ & $(0.029)$ & $(0.017)$ & $(0.024)$ & $(0.030)$ & $(0.028)$ \\
\hline Overall r ${ }^{2}$ & 0.010 & 0.055 & 0.012 & 0.036 & 0.014 & 0.037 \\
N & 3730 & 3730 & 3730 & 1862 & 1868 & 3738 \\
\hline \hline
\end{tabular}

Table 4: Random effects regressions to test for religious affinity. The data is from the religious affiliation condition. Models 11-13 are based on data from all senders, 14 and 15 are on senders without and with religious affiliation, respectively. Dependent variable BELIEF = stated probability by senders (by receivers) of receiver returning (or sender sending), and $W S E N D=W T D \times a_{\text {type }}+(1-W T D) \times a_{\text {default }}$. where $W T D=$ stated willingness to discriminate, $a_{\text {type }}=$ the conditional action chosen for a certain co-participant type, and $a_{\text {default }}=$ the default action. Random effects are at the participant level. Significance levels are denoted by *** for $p<0.01,{ }^{* *}$ for $p<0.05$, and ${ }^{*}$ for $p<0.1$. Standard errors are in parentheses. 
Hypothesis 3 posits that religious affiliation or religiosity can serve as social identities irrespective of creed. Result 1 suggests this, but a stricter test involves data from the religious affiliation condition where there is a clear demarcation of social identity for self and other. This test distinguishes itself from previous ones in that it considers the possibility that people trust each other more so long as they both have some religious affiliation, even if they are of different religious denominations. Figure 5 plots the linear fit of sender's beliefs in the trustworthiness of the receiver as a function of the sender's religiosity in the absence (left) or presence (right) of religious affinity, and shows the presence of religious affinity.

To test this formally, we derive the dummy variable AFFILIATE, which takes on a value of 1 when a participant who is religiously affiliated faces a task where the other is also religiously affiliated, regardless of creed. It takes on a value of zero when either the participant is an atheist or the task involves trusting an atheist. Referring to table 4, AFFILIATE is positive and significant in model 11, showing us that religious people believe that other religious people are trustworthier than atheists. However, it is insignificant in model 12, showing us that despite this belief they are not trusted more. Model 13 includes an AFFILIATE $\times$ RELI variable and finds that such beliefs are amplified by the sender's religiosity. Model 16 corroborates model 12 and further shows that there is no higher order effect on actions.

The effect of religious affinity on actions is weaker than that of being affiliated to the same denomination: in models 12 and 16, INGROUP and INGROUP $\times R E L I$ are positive and significant, while AFFILIATE and AFFILIATE $\times$ RELI are not. This supports the arguments presented in hypotheses 2 and 3 that connectedness enhances group identification. Beliefs only partially drive behaviour on the basis of mere religious affinity. Beyond statistical discrimination driven by beliefs, taste-based discrimination holds only if people are affiliated to the same denomination-not just by mere religious affinity. We further scrutinize the negative and significant INGROUP effect and its interaction term in model 13, which implies that religiosity diminishes the belief effect for those from the same denomination. This peculiar result of lower beliefs of trustworthiness in the ingroup is driven by atheists, as shown by our regressions on data disaggregated by atheists and religious affiliates (models 14 and 15 respectively). It suggests that atheists are more suspicious of each other, even though it does not lead to lower trust. In contrast, religious affiliates ultimately trust the ingroup more. These behaviors suggest taste-based discrimination.

Result 3 (Religious affinity). Senders' religiosity enhances beliefs about religiously affiliated receivers' trustworthiness regardless of whether or not they belong 


\begin{tabular}{||l||l|l||l||l||l|l||l|l||}
\hline \hline \multicolumn{1}{||c||}{} & \multicolumn{4}{c||}{ Senders } & \multicolumn{4}{c||}{ Receivers } \\
\hline & \multicolumn{2}{c||}{ Low stake } & \multicolumn{2}{c||}{ High stake } & \multicolumn{2}{c||}{ Low stake } & \multicolumn{2}{c||}{ High stake } \\
\hline \hline Category & $\rho$ & $p$ & $\rho$ & $p$ & $\rho$ & $p$ & $\rho$ & $p$ \\
\hline Gender & 0.089 & 0.146 & 0.142 & $0.020^{* *}$ & -0.014 & 0.825 & 0.026 & 0.676 \\
\hline Age & 0.149 & $0.015^{* *}$ & 0.047 & 0.449 & -0.066 & 0.288 & 0.062 & 0.318 \\
\hline Nationality & 0.117 & $0.057^{*}$ & 0.042 & 0.492 & 0.012 & 0.843 & 0.025 & 0.691 \\
\hline Religion & 0.127 & $0.038^{* *}$ & 0.178 & $0.004^{* * *}$ & 0.101 & 0.101 & 0.095 & 0.124 \\
\hline Religiosity & 0.115 & $0.060^{*}$ & 0.117 & $0.056^{*}$ & 0.040 & 0.518 & 0.115 & 0.063 \\
\hline Ethnicity & 0.193 & $0.002^{* * *}$ & 0.109 & $0.076^{*}$ & 0.083 & 0.177 & 0.002 & 0.969 \\
\hline Campus & 0.130 & $0.034^{* *}$ & 0.125 & $0.042^{* *}$ & 0.057 & 0.356 & 0.029 & 0.645 \\
\hline Course & 0.108 & $0.079^{*}$ & 0.111 & $0.070^{*}$ & 0.062 & 0.317 & 0.050 & 0.422 \\
\hline Politics & 0.121 & $0.048^{* *}$ & 0.083 & 0.178 & -0.060 & 0.334 & 0.046 & 0.454 \\
\hline Participation & 0.117 & $0.055^{*}$ & 0.024 & 0.702 & 0.042 & 0.498 & 0.000 & 0.998 \\
\hline Birthday & 0.091 & 0.137 & 0.118 & $0.054 *$ & 0.002 & 0.973 & 0.099 & 0.108 \\
\hline \hline
\end{tabular}

Table 5: Correlation between religiosity and willingness to discriminate for different categories. Spearman $\rho$ coefficients for and associated $p$-values given. The symbols ${ }^{* * *},{ }^{* *}$ and $*$ denote significance at or above the $0.01,0.05,0.1$ levels respectively.

to the same denomination, but they do not invest more trust despite this belief.

\subsection{General prejudice}

Hypothesis 4 posits that more religious people discriminate more over a range of social identities including non-religious ones. Our univariate tests examine whether more religious participants have relatively higher WTD across the different social identity categories we use. We construct, for each participant, an average WTD as the unweighted mean WTD across all of them. The correlation between average WTD and religiosity is positive and significant across both roles $(\rho=0.087$, $p=0.0449)$. This relationship is significant for senders $(\rho=0.123, p=0.0442)$ but insignificant for receivers $(\rho=0.045, p=0.4658)$. Further, the average religiosity of those whose WTD is zero throughout the experiment $(\mu=33.5, \mathrm{n}=73)$ is significantly less than that of others $(\mu=40.5, n=457, p=0.01)$. We also examine the correlation between religiosity and WTD across social categories (see table 5). Again, these correlations are generally insignificant for receivers. For senders, information on religious affiliation, religiosity and ethnicity are salient and serve as social identifiers that markedly separate participants. In turn, the correlations of religiosity and the WTD along these dimensions are robustly significant. Referring to table 6 , model 17 shows that WTD is positively related to religiosity, which suggests that more religious people are more prone to religious-based discrimination.

Further, we test if religious participants are generally more prone to ingroup favouritism, i.e. even if social identities of co-participants are unrelated to religion. 


\begin{tabular}{lccc}
\hline \hline & $(17)$ & $(18)$ & $(19)$ \\
& WTD & BELIEF & WSEND \\
& All & All & All \\
\hline STAKE & $0.013^{* *}$ & $-0.045^{* * *}$ & $-0.154^{* * *}$ \\
& $(0.005)$ & $(0.003)$ & $(0.005)$ \\
FEMALE & 0.021 & -0.006 & 0.047 \\
& $(0.023)$ & $(0.020)$ & $(0.035)$ \\
RELI & $0.031^{* *}$ & $0.033^{* *}$ & 0.000 \\
& $(0.015)$ & $(0.013)$ & $(0.022)$ \\
INGROUP & & $0.009^{* *}$ & $0.022^{* * *}$ \\
& & $(0.004)$ & $(0.006)$ \\
INGROUP & & -0.001 & 0.001 \\
by RELI & & $(0.005)$ & $(0.008)$ \\
BELIEF & & & $0.170^{* * *}$ \\
CONSTANT & $0.195^{* * *}$ & $0.410^{* * *}$ & $0.447^{* * *}$ \\
& $(0.016)$ & $(0.014)$ & $(0.025)$ \\
\hline Overall r ${ }^{2}$ & 0.010 & 0.016 & 0.060 \\
N & 5874 & 16438 & 16438 \\
\hline \hline
\end{tabular}

Table 6: Random effects regressions to test for general prejudice. The data is from the non-religion conditions. Models 17-19 are based on data from all senders. Dependent variable $W T D=$ stated willingness to discriminate, $B E L I E F=$ stated probability of receiver returning, and $W S E N D=W T D \times a_{\text {type }}+(1-W T D) \times a_{\text {default }}$, where $a_{\text {type }}=$ the conditional action chosen for a certain co-participant type, and $a_{\text {default }}=$ the default action. Random effects are at the participant level. Significance levels are denoted by ${ }^{* * *}$ for $p<0.01,{ }^{* *}$ for $p<0.05$, and ${ }^{*}$ for $p<0.1$. Standard errors are in parentheses. 


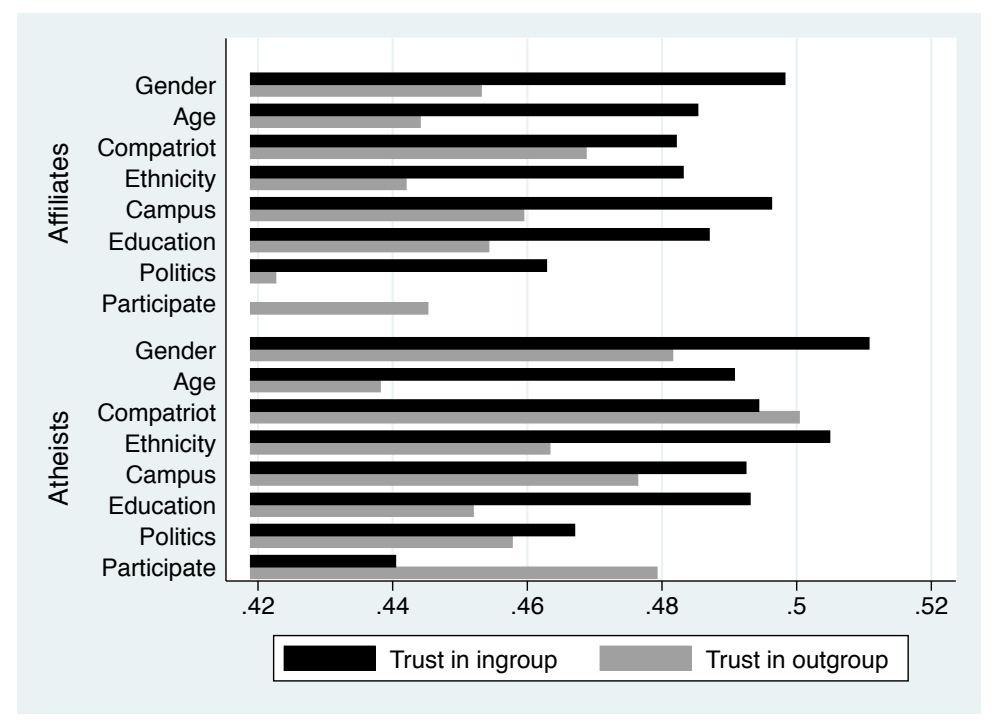

Figure 6: Group biases of religious affiliates and atheists across non-religious conditions. The figure shows the mean trust by senders conditional on receivers being of the same (ingroup) or a different (outgroup) type as them per category. Trust by religiously affiliated participants are grouped in the upper block, and trust by atheists are grouped in the lower block.

Figure 6 shows that both religious affiliates and atheists generally favour the ingroup over the outgroup by trusting the ingroup more across different categories of social identity. Models 17-19 test ingroup biases on data concerning all non-religion conditions. As found above, WTDs increase with religiosity (model 17). For beliefs (model 18), we find a positive and significant INGROUP effect for senders overall, but no RELI interaction effect. For actions (model 19), we also find a positive and significant INGROUP effect for senders overall, but no RELI interaction effect. This result is robust to controls for respective conditions. ${ }^{12}$

Result 4 (General prejudice). Religiosity is positively associated with the general willingness of senders to discriminate across a range of non-religious social identities. However, participants of different religiosity are as prone to ingroup favouritism.

\footnotetext{
${ }^{12}$ We also controlled for each category with condition-identifying dummies interacted with INGROUP to test the influence of religiosity on the extent of ingroup biases, as an alternative to the regressions disaggregated by religious affiliation. The same result holds: the willingness to discriminate increases with religiosity, but ingroup biases are generally invariant to religiosity. Please see the regressions in online appendix OA5.
} 


\section{Discussion}

Inter-religious interaction is an increasingly important social phenomenon. However, previous experimental work has yet to establish univocal evidence regarding its direct, independent effects on trust and trustworthiness. To better understand this issue we conducted a trust game experiment across three countries with participants of different religious denominations and levels of religiosity. Our experiment was designed to test four hypotheses for indirect effects of religiosity we derived from these previous studies. Taken together these hypotheses propose that religiosity affects economic behaviour indirectly by moderating (a) the way we treat others of the same and different social groups and (b) the expectations and behaviour those we interact with develop towards us.

Our main findings can be summarised as follows. First, religiosity is a strong social identifier (result 1) which is used as a basis of statistical discrimination by senders of varying religiosities. Both religious and non-religious people believe that more religious others are more trustworthy. Second, we found that religiosity enhances the ingroup favouritism people show to others who share the same faith (result 2). Senders of all religions believe receivers of the same faith to be more trustworthy and follow these beliefs with actions in step with their own degree of religiosity. Third, we found a religious fellow feeling or affinity between religious people across different faiths, i.e. irrespective of whether they share the same one or not (result 3). This was expressed in the greater belief people with religious affiliation have in the trustworthiness of others similarly affiliated. As before, individual religiosity amplifies this effect. This kind of religious affinity, however, does not generate quite the same positive effect on actual behaviour. Fourth, while we found that religiosity is associated with a willingness to discriminate across non-religious categories, observed ingroup favouritism did not vary with religiosity. Since the 1950s, Adorno et al. (1950) and Allport (1954) have postulated general religious prejudice, but have since been met with scant reliable evidence.

In summary, we uncovered evidence that religion operates indirectly through social identities and religious affiliation, which are used as a basis for discrimination in trust games. Religious identity is one dimension that tells decision makers how they are connected to those with whom they interact. The nature and degree of discrimination observed generally depended on the nature and degree of connectedness between individuals. The behavioural patterns we observed across the four main results showed that the closer people are the more they trust each other. Religious ingroup effects on beliefs carry over strongly to actions, in contrast to the weaker effect when religiosity was known but religious affiliation was unknown, and when religious affiliation was known (but) to be of a different creed. These 
effects increased with one's religiosity, which is an indicator of how rooted one is in a particular social group. We believe the diversity in our participant pool lends our results good domain validity. Our study is general, as opposed to creed-specific, also in its explanation for how religion affects behaviour.

In addition to the evidence relating to our hypotheses we generally found that people are willing to pay for the chance to discriminate, be it for statistical or taste motives. We designed an incentive-compatible measure of the willingness to discriminate which was shown to be significantly related to our other variables. We believe that our measure may be deployed in other social identity contexts to guide policy related to discrimination in labour markets and other specific areas.

To conclude, the social identities of people determine the nature and intensity of religious connectedness, and in turn trust and trustworthiness.

\section{Acknowledgements}

Project funding through the Religion \& Society Programme of the AHRC (Grant AH/F007779/1) is gratefully acknowledged. Simon Gächter acknowledges support under the European Research Council Advanced Investigator grant ERCAdG 295707 COOPERATION, and the ESRC-funded research Network of Integrated Behavioural Science (NIBS, ES/K002201/1).

\section{References}

Adorno, T. W., Frenkel-Brunswik, E., Levinson, D. and Sanford, N. (1950), The Authoritarian Personality, New York, NY: Harper and Row.

Akerlof, G. A. and Kranton, R. E. (2000), 'Economics and identity,' Quarterly Journal of Economics, vol. 115, 715-753.

Allport, G. W. (1954), The Nature of Prejudice, Cambridge, MA: Perseus Books.

Allport, G. W. and Ross, J. M. (1967), 'Personal religious orientation and prejudice,' Journal of Personality and Social Psychology, vol. 5, 432-443.

Altemeyer, B. and Hunsberger, B. (1992), 'Authoritarianism, religious fundamentalism, quest, and prejudice,' International Journal for the Psychology of Religion, vol. 2 (2), 113-133. 
Anderson, L., Mellor, J. and Milyo, J. (2010), 'Did the devil make them do it? the effects of religion in public goods and trust games,' Kyklos, vol. 63, 163-175.

Anderson, L. R., Fryer, R. G. and Holt, C. A. (2006), 'Discrimination: Experimental evidence from psychology and economics,' in W. M. Rodgers, ed., Handbook on the Economics of Discrimination, chap. 4, Edward Elgar.

Anderson, L. R. and Mellor, J. M. (2009), 'Religion and cooperation in a public goods experiment,' Economics Letters, vol. 105 (1), 58-60.

Aron, A., Aron, E. N., Tudor, M. and Nelson, G. (1991), 'Close relationships as including other in the self.' Journal of personality and social psychology, vol. 60 (2), 241.

Berg, J., Dickhaut, J. and McCabe, K. (1995), 'Trust, reciprocity, and social history,' Games and Economic Behavior, vol. 10 (1), 122-142.

Chen, Y. and Xin, S. (2009), 'Group identity and social preferences,' American Economic Review, vol. 99, 431-457.

Chuah, S. H., Fahoum, R. and Hoffmann, R. (2013), 'Fractionalization and trust in India: A field-experiment,' Economics Letters, vol. 119 (2), 191-194.

Chuah, S. H., Hoffmann, R., Jones, M. K. and Williams, G. A. (2009), 'An economic anatomy of culture: Attitudes and behaviour in inter- and intra-national ultimatum game experiments,' Journal of Economic Psychology, vol. 30 (5), 732 744 .

Chuah, S. H., Hoffmann, R., Ramasamy, B. and Tan, J. H. W. (2014), 'Religion, ethnicity and cooperation: An experimental study,' Journal of Economic Psychology, vol. 45, 33-43.

Croson, R. and Buchan, N. (1999), 'Gender and culture: International experimental evidence from trust games,' American Economic Review (Papers and Proceeedings), vol. 89 (2), 386-391.

Currarini, S. and Mengel, F. (August 6 2013), 'Identity, homophily and in-group bias,' Working paper.

DeJong, G. F., Faulkner, J. E. and Warland, R. H. (1976), 'Dimensions of religiosity reconsidered: Evidence form a cross-cultural study,' Social Forces, vol. 54 (4), 866-889. 
Falk, A. and Zehnder, C. (2013), 'A city-wide experiment on trust discrimination,' Journal of Public Economics, vol. 100, 15-27.

Farnham, S. D., Greenwald, A. G. and Banaji, M. R. (1999), 'Implicit self-esteem,' in D. Abrams and M. A. Hogg, eds., Social identity and social cognition, Malden, UK: Blackwell, pp. 230-248.

Fehr, E., Fischbacher, U., Schupp, J., von Rosenbladt, B. and Wagner, G. G. (2002), 'A nationwide laboratory examining trust and trustworthiness by integrating behavioural experiments into representative surveys,' Schmollers Jahrbuch, vol. 122, 519-542.

Fershtman, C. and Gneezy, U. (2001), 'Discrimination in a segmented society: An experimental approach,' The Quarterly Journal of Economics, vol. 116 (1), 351377.

Glock, C. Y. and Stark, R. (1965), Religion and society in tension, Chicago: Rand McNally.

Grim, B. J., ed. (2014), Religious Hostilities Reach Six-Year High, Pew Research Center.

Guiso, L., Sapienza, P. and Zingales, L. (2003), 'People's opium? religion and economic attitudes,' Journal of Monetary Economics, vol. 50 (1), 225-282.

Guiso, L., Sapienza, P. and Zingales, L. (2006), 'Does culture affect economic outcomes?' Journal of Economic Perspectives, vol. 20 (2), 23-48.

Herrmann, B., Thöni, C. and Gächter, S. (2008), 'Antisocial punishment across societies,' Science, vol. 319 (5868), 1362-1367.

Hill, P. C. and Hood, R. W., eds. (1999), Measures of Religiosity, Birmingham, AL: Religious Education Press.

Hoffmann, R. (2013), 'The experimental economics of religion,' Journal of Economic Surveys, vol. 27 (5), 813-845.

Holm, H. J. and Danielson, A. (2005), 'Tropic trust versus nordic trust: Experimental evidence from Tanzania and Sweden,' Economic Journal, vol. 115 (503), 505-532.

Hunsberger, B. (1996), 'Religious fundamentalism, right-wing authoritarianism, and hostility toward homosexuals in non-Christian religious groups,' International Journal for the Psychology of Religion, vol. 6 (1), 39-49. 
Hunsberger, B. and Jackson, L. (2005), 'Religion, meaning, and prejudice,' Journal of Social Issues, vol. 61, 807-826.

Huntington, S. P. (1996), The Clash of Civilizations and the Remaking of World Order, Simon \& Schuster.

Iannaccone, L. R. (1998), 'Introduction to the economics of religion,' Journal of economic literature, $1465-1495$.

Inglehart, R. (1997), Modernization and Postmodernization: Cultural, Economic, and Political Change in 43 Societies, Princeton: Princeton University Press.

Jackson, L. M. and Hunsberger, B. (1999), 'An intergroup perspective on religion and prejudice,' The International Journal for the Psychology of Religion, vol. 38 (4), 509-523.

Johnson, N. D. and Mislin, A. A. (2011), 'Trust games: A meta-analysis,' Journal of Economic Psychology, vol. 32 (5), 865-889.

Karlan, D. S. (2005), 'Using experimental economics to measure social capital and predict financial decisions,' American Economic Review, vol. 95 (5), 1688-1699.

Laurenceau, J. P., Barrett, L. F. and Pietromonaco, P. R. (1998), 'Intimacy as an interpersonal process: the importance of self-disclosure, partner disclosure, and perceived partner responsiveness in interpersonal exchanges.' Journal of Personality and Social Psychology, vol. 74 (5), 1238.

Marquardt, D. W. (1980), 'Comment: You should standardize the predictor variables in your regression models,' Journal of the American Statistical Association, vol. 75 (369), 87-91.

Mueser, P. (1999), 'Discrimination,' in J. Eatwell, M. Milgate and P. Newman, eds., Social Economics, The New Palgrave Dictionary of Economics, McMillan, pp. 24-30.

Rohrbaugh, J. and Jessor, R. (1975), 'Religiosity in youth: A personal control against deviant behavior,' Journal of Personality, vol. 43 (1), 136-155.

Roth, A. E., Prasnikar, V., Okuno-Fujiwara, M. and Zamir, S. (1991), 'Bargaining and market behavior in jerusalem, ljubljana, pittsburgh, and tokyo: An experimental study,' The American Economic Review, 1068-1095. 
Ryan, R. M., Scott Rigby, S. and King, K. (1993), 'Two Types of Religious Internalization and Their Relations to Religious Orientations and Mental Health,' Journal of Personality and Social Psychology, vol. 65 (3), 586-596.

Selten, R. (1967), 'Die Strategiemethode zur Erforschung des eingeschränkt rationalen Verhaltens im Rahmen eines Oligopolexperiments,' in H. Sauermann, ed., Beiträge zur experimentellen Wirtschaftsforschung, vol. I, Tübingen, Germany: J.C.B. Mohr (Siebeck), pp. 136-168.

Selten, R. (1998), 'Axiomatic characterization of the quadratic scoring rule,' $E x$ perimental Economics, vol. 1 (1), 43-61.

Smurda, J. D., Wittig, M. A. and Gokalp, G. (2006), 'Effects of threat to a valued social identity on implicit self-esteem and discrimination,' Group Processes 83 Intergroup Relations, vol. 9 (2), 181-197.

Spilka, B., Hood, R. W., Hunsberger, B. and Gorsuch, R. (2003), The Psychology of Religion, New York, NY: Guildford Press.

Tan, J. H. W. (2006), 'Religion and social preferences: An experimental study,' Economics Letters, vol. 90 (1), 60-67.

Tan, J. H. W. (2014), 'Behavioral economics of religion,' in P. Oslington, ed., Oxford Handbook of Christianity and Economics, Oxford, UK: Oxford University Press.

Tan, J. H. W. and Vogel, C. (2008), 'Religion and trust: An experimental study,' Journal of Economic Psychology, vol. 29 (6), 832-848.

The Institute for Economics and Peace (2014), Global Terrorism Index. 


\section{APPENDIX}

A1) Distribution of subject types in each condition across three locations and WTD, beliefs and actions across conditions and types by roles and locations

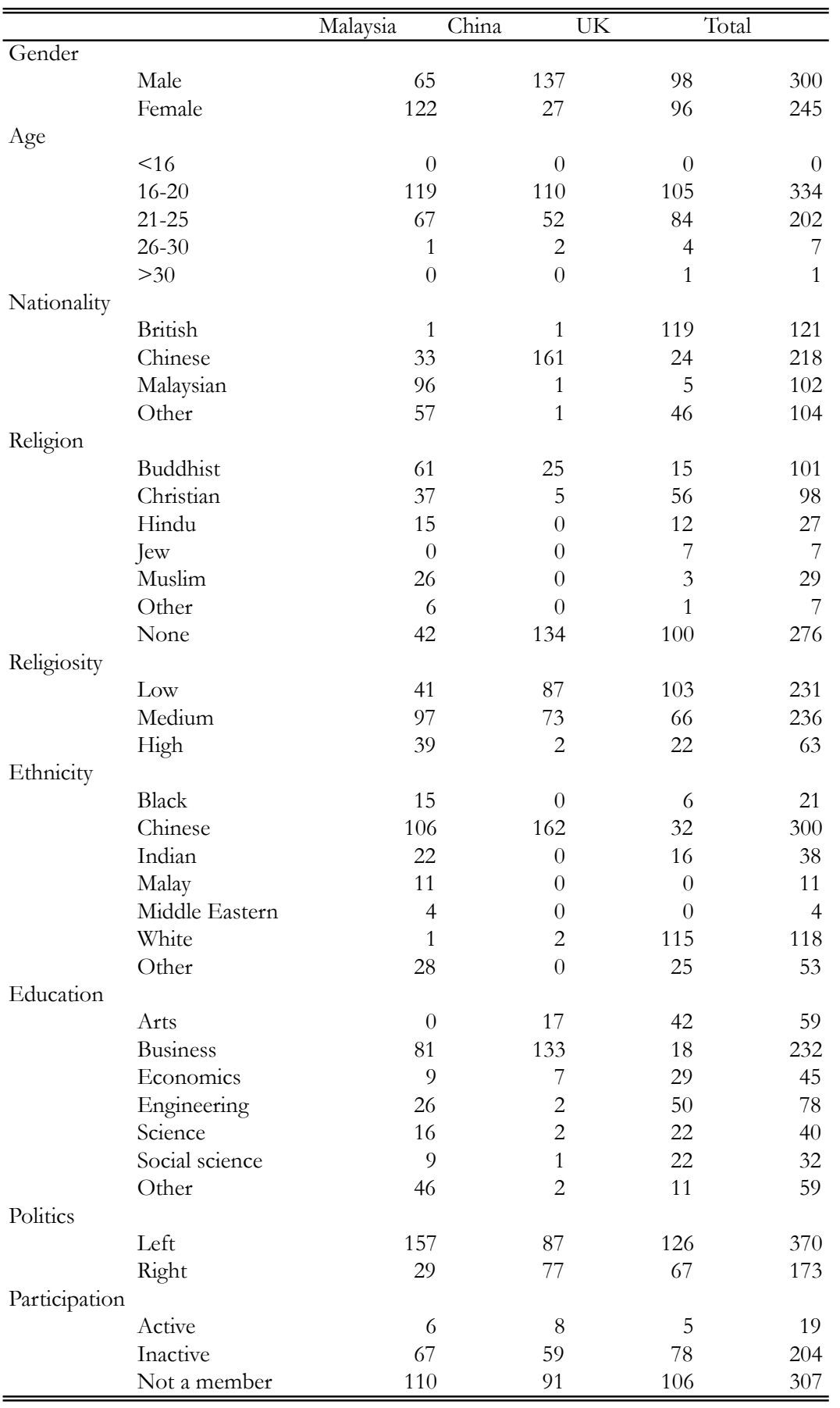




\begin{tabular}{|c|c|c|c|c|c|c|c|}
\hline \multirow{12}{*}{849} & \multirow{2}{*}{$\begin{array}{l}\text { WTD } \\
\text { Gender }\end{array}$} & $\begin{array}{l}\text { Malaysia } \\
\text { Sender } \\
\end{array}$ & Receiver & $\begin{array}{l}\text { China } \\
\text { Sender }\end{array}$ & Receiver & \multirow[t]{2}{*}{$\begin{array}{l}\text { UK } \\
\text { Sender } \\
\end{array}$} & Receiver \\
\hline & & 0.31 & 0.25 & 0.21 & 0.28 & & 0.17 \\
\hline & Age & 0.31 & 0.22 & 0.23 & 0.26 & 0.18 & 0.17 \\
\hline & Nationality & 0.25 & 0.23 & 0.21 & 0.23 & 0.14 & 0.16 \\
\hline & Religion & 0.25 & 0.24 & 0.24 & 0.26 & 0.15 & 0.17 \\
\hline & Religiosity & 0.26 & 0.16 & 0.21 & 0.27 & 0.15 & 0.18 \\
\hline & Ethnicity & 0.30 & 0.26 & 0.23 & 0.29 & 0.13 & 0.14 \\
\hline & Campus & 0.30 & 0.24 & 0.23 & 0.29 & 0.14 & 0.16 \\
\hline & Education & 0.31 & 0.25 & 0.29 & 0.27 & 0.18 & 0.17 \\
\hline & Politics & 0.21 & 0.14 & 0.18 & 0.21 & 0.14 & 0.16 \\
\hline & Participation & 0.26 & 0.16 & 0.24 & 0.26 & 0.14 & 0.15 \\
\hline & Birthday & 0.25 & 0.18 & 0.17 & 0.21 & 0.11 & 0.14 \\
\hline
\end{tabular}




\begin{tabular}{|c|c|c|c|c|c|c|c|c|}
\hline \multirow[t]{2}{*}{ Beliefs } & & \multicolumn{2}{|l|}{ Malaysia } & \multicolumn{2}{|l|}{ China } & \multicolumn{3}{|l|}{ UK } \\
\hline & & Sender & Receiver & Sender & Receiver & Sender & & Receiver \\
\hline \multicolumn{9}{|l|}{ Baseline } \\
\hline & & 0.46 & 0.44 & 0.44 & 0.47 & & 0.36 & 0.39 \\
\hline \multicolumn{9}{|l|}{ Gender } \\
\hline & Male & 0.46 & 0.44 & 0.44 & 0.47 & & 0.36 & 0.39 \\
\hline & Female & 0.45 & 0.46 & 0.49 & 0.49 & & 0.35 & 0.38 \\
\hline \multicolumn{9}{|l|}{ Age } \\
\hline & $<16$ & 0.32 & 0.36 & 0.37 & 0.43 & & 0.30 & 0.32 \\
\hline & $16-20$ & 0.46 & 0.46 & 0.40 & 0.49 & & 0.35 & 0.38 \\
\hline & $21-25$ & 0.51 & 0.48 & 0.44 & 0.49 & & 0.35 & 0.39 \\
\hline & $26-30$ & 0.37 & 0.41 & 0.38 & 0.43 & & 0.34 & 0.35 \\
\hline & $>30$ & 0.32 & 0.32 & 0.41 & 0.38 & & 0.34 & 0.32 \\
\hline \multicolumn{9}{|c|}{ Nationality } \\
\hline & Same & 0.46 & 0.44 & 0.44 & 0.47 & & 0.36 & 0.39 \\
\hline & Different & 0.45 & 0.46 & 0.48 & 0.51 & & 0.35 & 0.37 \\
\hline \multicolumn{9}{|l|}{ Religion } \\
\hline & Buddhist & 0.38 & 0.43 & 0.37 & 0.42 & & 0.34 & 0.35 \\
\hline & Christian & 0.29 & 0.33 & 0.33 & 0.40 & & 0.29 & 0.29 \\
\hline & Hindu & 0.43 & 0.50 & 0.49 & 0.48 & & 0.38 & 0.40 \\
\hline & Jew & 0.40 & 0.42 & 0.45 & 0.45 & & 0.41 & 0.42 \\
\hline & Muslim & 0.35 & 0.36 & 0.36 & 0.37 & & 0.34 & 0.35 \\
\hline & Other & 0.33 & 0.34 & 0.33 & 0.38 & & 0.31 & 0.31 \\
\hline & None & 0.32 & 0.36 & 0.37 & 0.43 & & 0.28 & 0.33 \\
\hline \multicolumn{9}{|c|}{ Religiosity } \\
\hline & Low & 0.34 & 0.38 & 0.34 & 0.40 & & 0.29 & 0.34 \\
\hline & Medium & 0.44 & 0.39 & 0.42 & 0.43 & & 0.36 & 0.38 \\
\hline & High & 0.41 & 0.41 & 0.48 & 0.47 & & 0.41 & 0.41 \\
\hline \multicolumn{9}{|c|}{ Ethnicity } \\
\hline & Black & 0.38 & 0.38 & 0.33 & 0.41 & & 0.32 & 0.34 \\
\hline & Chinese & 0.39 & 0.38 & 0.36 & 0.43 & & 0.35 & 0.33 \\
\hline & Indian & 0.46 & 0.46 & 0.44 & 0.48 & & 0.33 & 0.39 \\
\hline & Malay & 0.34 & 0.36 & 0.33 & 0.40 & & 0.31 & 0.33 \\
\hline & Middle Easte: & 0.43 & 0.47 & 0.46 & 0.51 & & 0.34 & 0.38 \\
\hline & White & 0.39 & 0.41 & 0.37 & 0.40 & & 0.33 & 0.34 \\
\hline & Other & 0.34 & 0.34 & 0.31 & 0.38 & & 0.31 & 0.33 \\
\hline \multicolumn{9}{|l|}{ Campus } \\
\hline & Malaysia & 0.49 & 0.51 & 0.39 & 0.46 & & 0.34 & 0.35 \\
\hline & China & 0.42 & 0.46 & 0.46 & 0.50 & & 0.33 & 0.36 \\
\hline & UK & 0.47 & 0.50 & 0.47 & 0.50 & & 0.33 & 0.40 \\
\hline \multicolumn{9}{|c|}{ Education } \\
\hline & Arts & 0.42 & 0.44 & 0.44 & 0.47 & & 0.31 & 0.34 \\
\hline & Business & 0.44 & 0.42 & 0.38 & 0.43 & & 0.32 & 0.34 \\
\hline & Economics & 0.46 & 0.47 & 0.43 & 0.42 & & 0.34 & 0.37 \\
\hline & Engineering & 0.42 & 0.42 & 0.37 & 0.42 & & 0.32 & 0.33 \\
\hline & Science & 0.40 & 0.44 & 0.39 & 0.43 & & 0.35 & 0.37 \\
\hline & Social science & 0.44 & 0.46 & 0.44 & 0.49 & & 0.30 & 0.35 \\
\hline & Other & 0.37 & 0.35 & 0.33 & 0.40 & & 0.32 & 0.34 \\
\hline \multicolumn{9}{|l|}{ Politics } \\
\hline & Left & 0.39 & 0.41 & 0.38 & 0.50 & & 0.35 & 0.38 \\
\hline & Right & 0.46 & 0.44 & 0.42 & 0.47 & & 0.30 & 0.35 \\
\hline \multicolumn{9}{|c|}{ Participation } \\
\hline & Active & 0.45 & 0.46 & 0.50 & 0.55 & & 0.42 & 0.45 \\
\hline & Inactive & 0.43 & 0.41 & 0.38 & 0.42 & & 0.34 & 0.36 \\
\hline & Not a membe & 0.39 & 0.39 & 0.38 & 0.42 & & 0.30 & 0.33 \\
\hline \multicolumn{9}{|l|}{ Birthday } \\
\hline & Odd & 0.46 & 0.47 & 0.44 & 0.52 & & 0.34 & 0.40 \\
\hline & Even & 0.48 & 0.47 & 0.46 & 0.49 & & 0.34 & 0.39 \\
\hline
\end{tabular}




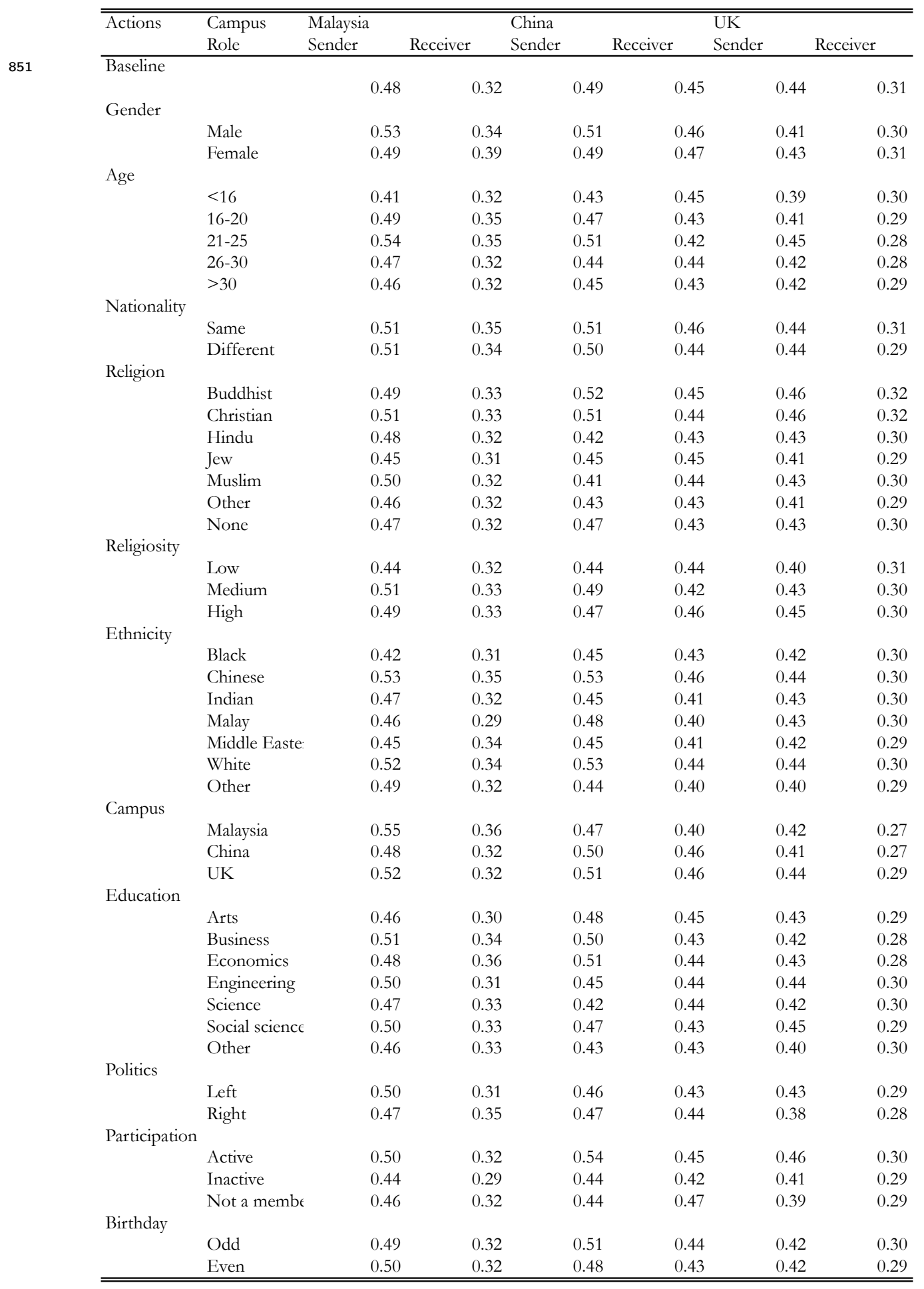


A2) Religiosity does not increase trust or trustworthiness

852

\begin{tabular}{lcc}
\hline \hline & & \\
& WSEND & WRETURN \\
& All & All \\
\hline \multirow{3}{*}{ BELIEF } & & \\
& 0.498 & 0.06 \\
STAKE & $(0.344)$ & $(0.545)$ \\
& $-0.783^{* * *}$ & $-0.979^{* * *}$ \\
FEMALE & $(0.183)$ & $(0.248)$ \\
& 0.229 & -0.104 \\
RELI & $(0.181)$ & $(0.318)$ \\
& -0.011 & -0.166 \\
CONSTANT & $(0.113)$ & $(0.192)$ \\
& 0.007 & -0.39 \\
LL & $(0.197)$ & $(0.309)$ \\
N & -46.851 & -308.114 \\
\hline \hline
\end{tabular}

Random effects regressions to test for religiosity effects. The data is from the religious affiliation condition. For senders, we use the dependent variable WSEND $=W T D * a_{\text {type }}+(1-$ $W T D) * a_{\text {default }}$, where $W T D=$ stated willingness to discriminate, $a_{\mathrm{type}}=$ the conditional action chosen for a certain receiver type, and $a_{\text {default }}=$ the default action. For receivers, the dependent variable is WRETURN, and computed as such. Random effects are at the participant level. Significance levels are denoted by $* * *$ for $p<0.01$, ** for $p<0.05$, and $*$ for $p<0.1$. Standard errors are in parentheses. 


\section{A3) Ingroup favoritism is consistent across religious denominations}

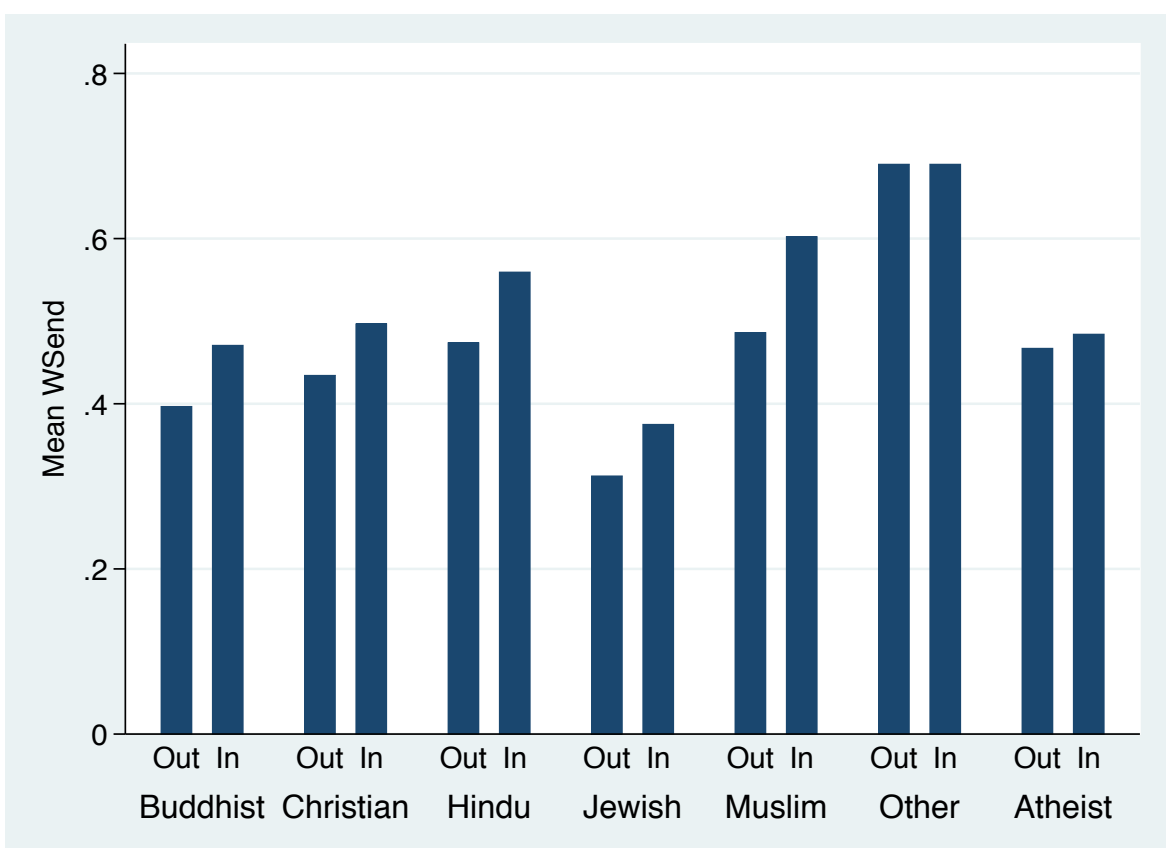

\begin{tabular}{cccccccc}
\hline \hline & Buddhist & Christian & Hindu & Jew & Muslim & Other & None \\
\hline Outgroup & 0.40 & 0.43 & 0.47 & 0.31 & 0.49 & 0.69 & 0.47 \\
& $(0.02)$ & $(0.02)$ & $(0.03)$ & $(0.06)$ & $(0.04)$ & $(0.06)$ & $(0.01)$ \\
Ingroup & 0.47 & 0.50 & 0.56 & 0.38 & 0.60 & 0.69 & 0.48 \\
& $(0.04)$ & $(0.05)$ & $(0.08)$ & $(0.18)$ & $(0.08)$ & $(0.15)$ & $(0.03)$ \\
\hline \hline
\end{tabular}

Note: Standard errors are in parentheses.

\section{A4) Table of main regression variables}

\begin{tabular}{lll}
\hline \hline Variable & Values & Description \\
\hline WTD & 0 to 1 & Percentage spent on implementing action conditional on co-participant's type. \\
BELIEF & 0 to 1 & Sender's (reciever's) stated belief that receiver's (sender's) will return (send). \\
WSEND & 0 to 1 & WTD * conditional action $+(1-W T D) *$ default action. \\
RISK & 0 or 1 & 0 for low risk game, 1 for high risk game. \\
FEMALE & 0 or 1 & 0 if male, 1 if female. \\
RELI & -1.48 to 2.27 & Participant's religiosity, mean centered average of items from religiosity inventory. \\
RLEV & 0,1 or 2 & Co-participant's religiosity level, 0 if low, 1 if medium, 2 if high. \\
INGROUP & 0 or 1 & 0 if co-participant is of a different type than the self, 1 if of the same type. \\
AFFILIATE 0 or 1 & 0 if participant or co-participant are atheists, 1 if both have a religion. \\
\hline \hline
\end{tabular}


A5) Regressions for ingroup biases in non-religious categories with conditionspecific ingroup dummies "IN[condition]"

854

\begin{tabular}{|c|c|c|c|}
\hline & $\begin{array}{c}W T D \\
\text { All }\end{array}$ & $\begin{array}{c}\text { BELIEF } \\
\text { All }\end{array}$ & $\begin{array}{c}\text { WSEND } \\
\text { All }\end{array}$ \\
\hline$S T A K E$ & $\begin{array}{c}0.019^{* * *} \\
(0.003)\end{array}$ & $\begin{array}{c}-0.048^{* * *} \\
(0.003)\end{array}$ & $\begin{array}{c}-0.154^{* * *} \\
(0.005)\end{array}$ \\
\hline FEMALE & $\begin{array}{c}0.017 \\
(0.025)\end{array}$ & $\begin{array}{l}-0.009 \\
(0.021)\end{array}$ & $\begin{array}{c}0.05 \\
(0.035)\end{array}$ \\
\hline RELI & $\begin{array}{c}0.035 * * \\
(0.016)\end{array}$ & $\begin{array}{c}0.027 * * \\
(0.013)\end{array}$ & $\begin{array}{c}0 \\
(0.022)\end{array}$ \\
\hline$I N A G E$ & $\begin{array}{c}0.007 \\
(0.007)\end{array}$ & $\begin{array}{c}0.051 * * * \\
(0.007)\end{array}$ & $\begin{array}{c}0.011 \\
(0.011)\end{array}$ \\
\hline INGENDER & $\begin{array}{c}0.029 * * * \\
(0.005)\end{array}$ & $\begin{array}{l}0.009 * \\
(0.005)\end{array}$ & $\begin{array}{c}-0.01 \\
(0.008)\end{array}$ \\
\hline INNATIONALITY & $\begin{array}{l}-0.008 \\
(0.007)\end{array}$ & $\begin{array}{c}0.053^{* * *} \\
(0.007)\end{array}$ & $\begin{array}{c}0.012 \\
(0.012)\end{array}$ \\
\hline INETHNICITY & $\begin{array}{c}0.017 * * * \\
(0.004)\end{array}$ & $\begin{array}{l}-0.005 \\
(0.004)\end{array}$ & $\begin{array}{c}0.003 \\
(0.007)\end{array}$ \\
\hline INCAMPUS & $\begin{array}{c}0.015^{* * *} \\
(0.006)\end{array}$ & $\begin{array}{c}0.043^{* * *} \\
(0.006)\end{array}$ & $\begin{array}{l}0.008 \\
(0.01)\end{array}$ \\
\hline INEDUCATION & $\begin{array}{c}0.050^{* * *} \\
(0.004)\end{array}$ & $\begin{array}{c}0.012^{* * *} \\
(0.004)\end{array}$ & $\begin{array}{c}0.001 \\
(0.007)\end{array}$ \\
\hline INPOLITICS & $\begin{array}{c}-0.031 * * * \\
(0.007)\end{array}$ & $\begin{array}{l}0.013^{*} \\
(0.007)\end{array}$ & $\begin{array}{l}-0.016 \\
(0.011)\end{array}$ \\
\hline INP ARTICIP ATION & $\begin{array}{c}0.007 \\
(0.006)\end{array}$ & $\begin{array}{c}0.029 * * * \\
(0.006)\end{array}$ & $\begin{array}{c}-0.014 \\
(0.01)\end{array}$ \\
\hline INGROUP & & $\begin{array}{l}-0.003 \\
(0.003)\end{array}$ & $\begin{array}{c}0.025^{* * *} * \\
(0.006)\end{array}$ \\
\hline INGROUP by RELI & & $\begin{array}{c}0.005 \\
(0.004)\end{array}$ & $\begin{array}{c}0.007 \\
(0.007)\end{array}$ \\
\hline BELIEF & & & $\begin{array}{c}0.161 \text { *** } \\
(0.011)\end{array}$ \\
\hline CONSTANT & $\begin{array}{c}0.188^{* * *} \\
(0.017)\end{array}$ & $\begin{array}{c}0.398^{* * *} \\
(0.014)\end{array}$ & $\begin{array}{c}0.449 * * * \\
(0.025)\end{array}$ \\
\hline Overall $r^{2}$ & 0.016 & 0.02 & 0.06 \\
\hline$N$ & 22962 & 21770 & 21770 \\
\hline
\end{tabular}

Random effects regressions to test for non-religious condition-specific ingroup effects. The data is from the non-religious conditions on senders. We use the dependent variable $W S E N D=W T D * a_{\mathrm{type}}+(1-W T D) * a_{\text {default }}$, where $W T D=$ stated willingness to discriminate, $a_{\mathrm{type}}=$ the conditional action chosen for a certain receiver type, and $a_{\text {default }}=$ the default action. Random effects are at the participant level. Significance levels are denoted by $* * *$ for $p<0.01$, ** for $p<0.05$, and $*$ for $p<0.1$. Standard errors are in parentheses. 